\title{
Distribution and Density of Monoamine Receptors in the Primate Visual Cortex Devoid of Retinal Input from Early Embryonic Stages
}

\author{
Pasko Rakic and Michael S. Lidow \\ Section of Neurobiology, Yale University School of Medicine, New Haven, Connecticut 06510
}

\begin{abstract}
Developmental mechanisms that regulate the areal and laminar distribution of various macromolecules, including neurotransmitter receptors in the cerebral cortex, are not known. In the present study, we examined the development of monoaminergic receptors in the rhesus monkey striate and peristriate visual cortex in the absence of input from the retina. Binocular enucleation was performed between embryonic days E60 and E81, prior to the ingrowth of geniculocortical fibers into the cortical plate and before genesis of the granular and supragranular layers of the visual cortex. The animals were delivered at term (E165) and sacrificed at 2 or 12 months of age, and their brains frozen and the occipital lobes cut at $20 \mu \mathrm{m}$ in the coronal plane. Cortical binding of ${ }^{3} \mathrm{H}$-clonidine, ${ }^{125} \mathrm{I}$-pindolol, ${ }^{3} \mathrm{H}-5-\mathrm{HT}$, ${ }^{3} \mathrm{H}-k$ etanserin, ${ }^{3} \mathrm{H}$-spiperone, ${ }^{3} \mathrm{H}-\mathrm{SCH} 23390$, and ${ }^{3} \mathrm{H}$-prazosin that label various monoamine receptors were autoradiographically visualized and quantified using a computer imaging system. All radioligands displayed specific laminar patterns in the striate and prestriate areas in both groups of animals. The areal and laminar distribution in the anophthalmic monkeys was similar to that in the controls. Significantly, in all enucleated animals, just as in the controls, a particularly high denslty of ${ }^{3} \mathrm{H}$-clonidine and ${ }^{3} \mathrm{H}$-prazosin was observed in the sublayers of layer IV involved in color vision. The present results show that the monoamine receptors in primate visual cortex can establish and maintain distinct laminar and areal patterns in the absence of activity or molecular cues originated from the retina, and provide new insight into the cortical consequences of secondary congenital anophthalmia.
\end{abstract}

[Key words: neurotransmitter receptors, striate cortex, development, rhesus monkey]

In recent years, numerous studies have indicated that developmental programs operating within cortical neurons, as well as inductive cues from various afferent systems, play a synergistic role in cortical specification (Wiesel, 1982; Rakic, 1988; Jones, 1990; Shatz, 1990; McConnell, 1991; O'Leary et al., 1994). However, the relative contributions and molecular mechanisms underlying these interactions in laminar and areal specification of the cerebral cortex are still unknown. The interaction between

\footnotetext{
Received May 6, 1994; revised Sept. 29, 1994; accepted Dec. 13, 1994.

This work was supported by the U.S. Public Health Service. Pregnant monkeys were obtained from Yale University Medical School Breeding Colony and

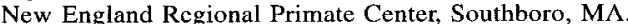

Correspondence should be addressed to Pasko Rakic, Section of Neurobiology, Yale University School of Medicine, 333 Cedar Street, New Haven, CT 06510 .

Copyright $\odot 1995$ Society for Neuroscience $0270-6474 / 95 / 152561-14 \$ 05.00 / 0$
}

neurotransmitters and corresponding receptors during early developmental stages was suggested as one among many components of this complex process, but so far little has been explored experimentally in vivo (see reviews by Mattson, 1988; Lauder, 1993).

The striate and peristriate cortex in primates can be used to test the role of the periphery on cortical development because these two areas display remarkable differences in laminar organization, constellation of cell classes, pattern of synaptic connectivity, and distribution of various macromolecules, including neurotransmitter receptors (e.g., Lund, 1988; Rakic et al., 1988; Felleman and Van Essen, 1991). For example, the color opponent system and the so-called "broad band" system of spatial information processing in primates consist of distinct neuronal populations initially identified physiologically (e.g., Wiesel and Hubel, 1966; DeValois and DeValois, 1975). The segregation of these two parallel systems is maintained from the retina to the parvocellular (P) and magnocellular (M) layers of the lateral geniculate nucleus, and then via geniculocortical projections to specific cortical layers involved predominately in color and orientation/motion discrimination (e.g., DeYoe and Van Essen, 1988; Livingstone and Hubel, 1988). The sublayer IVC $\alpha$ is the magnocellular recipient zone and IVA and IVC $\beta$ receive input from parvocellular layers of the lateral geniculate nucleus (Livingstone and Hubel, 1988). While delineation of their exact physiological functions remains to be elucidated, several lines of evidence revealed important psychophysiological differences between M and P systems (Schein and deMonasterio, 1987) that can be differentiated by the number of anatomical and cytological criteria (DeYoe and Van Essen, 1988; Livingstone and Hubel, 1988; Lund, 1988; Ts'o and Gilbert, 1988). M and P visual subsystem-specific cytoarchitectonic features in macaque monkey display clear and abrupt changes at the border between striate and extrastriate areas (Lund, 1988). Most importantly, a majority of neurotransmitter receptors in the rhesus monkey display region-specific laminar binding properties that can be correlated with the pattern of cellular layers and their input-output relationships in visual areas (Rakic et al., 1988). Recently, the timetable for the emergence of these receptors and changes in their pattern of distribution during prenatal and postnatal development was determined in this species (Lidow and Rakic, 1992, 1994).

In the present study, we examined the distribution of the seven monoamine receptor-specific ligands in the occipital cortex of animals that were binocularly enucleated as fetuses, starting from the first third of gestation. Although not engaged directly in signal transmission within the retino-geniculo-cortical synaptic chain, different subtypes of monoamine receptors are thought to be involved in modulation of cortical activity by spe- 
Table 1. Protocols of saturation autoradiographic assays

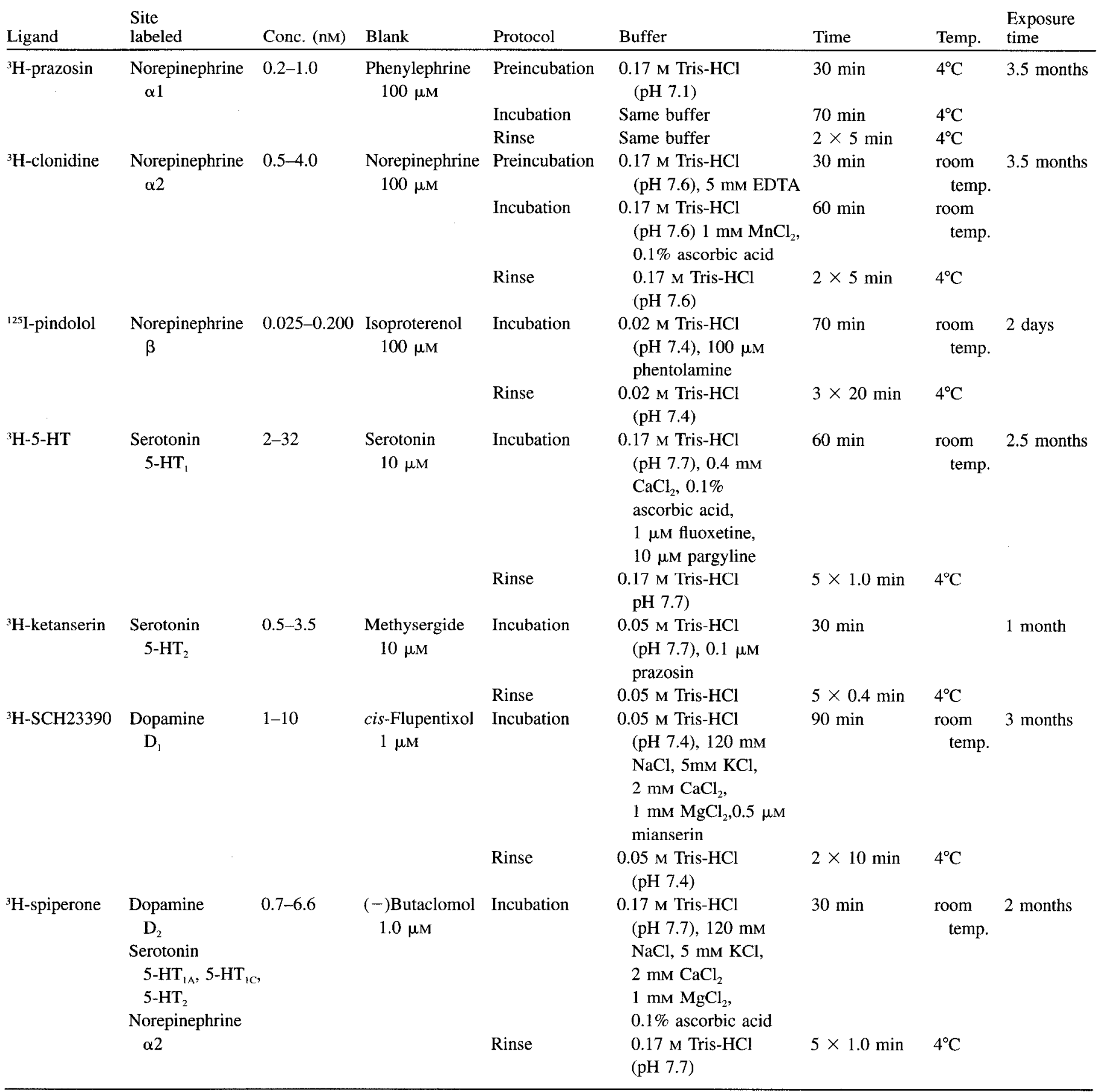

cific afferents (Fallon and Loughlin, 1987). Therefore, one may expect that the density and distribution of these receptors may be related to the level of activity in primary visual pathways. Furthermore, monoamines originating from the brainstem arrive early to the embryonic telencephalon where they may have a regulatory role on the differentiation of neurons (Lauder et al., 1982; Parnavelas and Blue, 1982; Mattson, 1988; Whitaker-Azmatia, 1991; Lauder, 1993). In the cortex of adult primates, there are significant areal and laminar-specific differences in the distribution of monoamines (Brown and Goldman-Rakic, 1977; Morrison et al., 1982; Levitt et al., 1984) and monoamine re- ceptors (Rakic et al., 1988). Recently we found that several monoamine receptors appear early in the transient embryonic zones of the fetal telencephalon, with particularly high density localized in the subplate zone subjacent to the prospective area 17 where it can be detected before areal differences appears in the overlaying cortical plate (Lidow and Rakic, 1994). Our major goal was to examine how these receptors develop, become distributed, and are maintained in the absence of input from the retina, and thus, to learn about the extent to which input from the retina induces and maintains laminar and areal organization of monoaminergic receptors. 

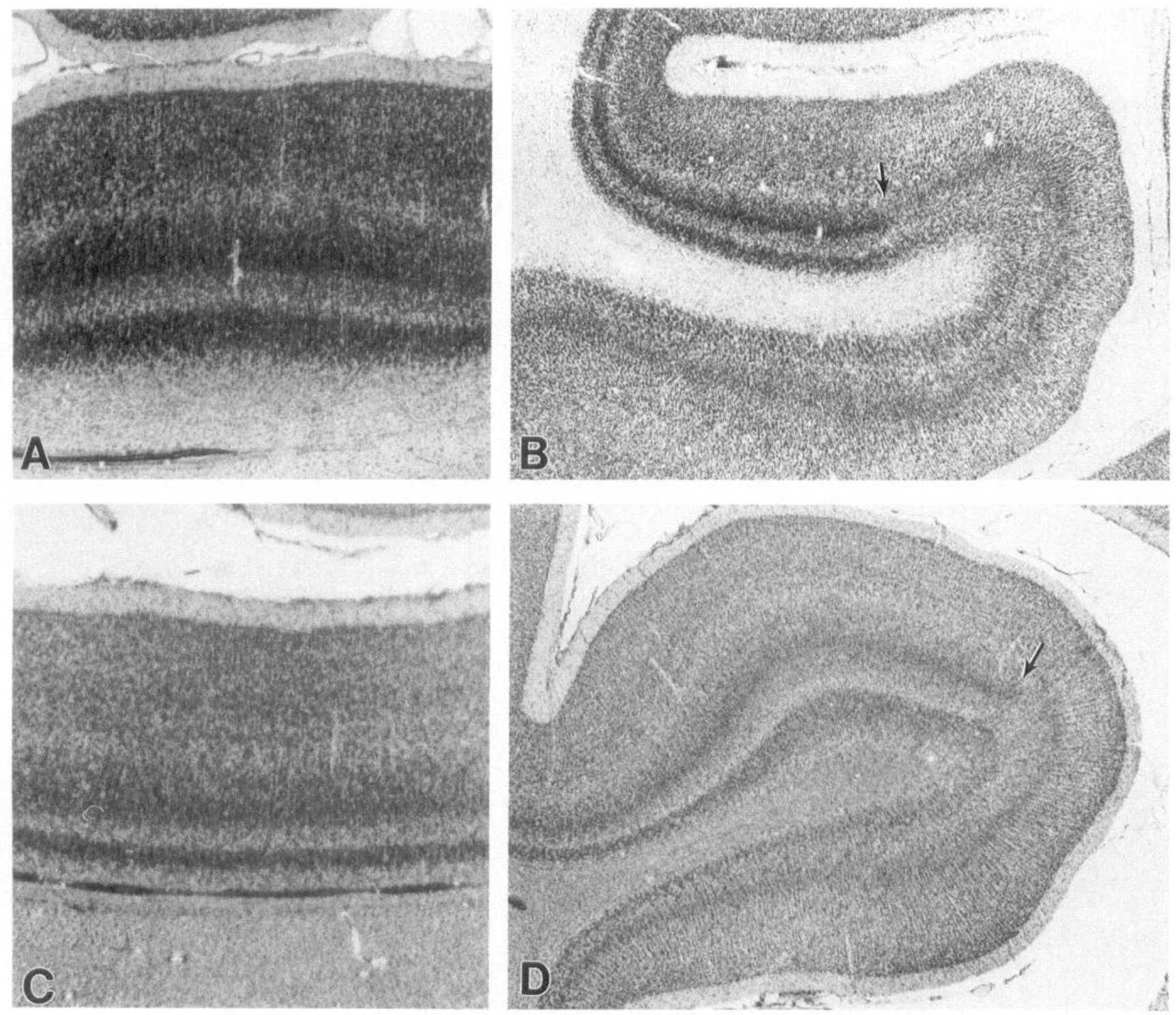

Figure 1. Cresyl violet-stained sections of visual cortex of normal $(A, B)$ and anophthalmic $(C, D)$ rhesus monkeys, both 2 months old. Note the similarity between the cytoarchitecture of visual cortex in normal controls $(A, B)$ and ophthalmic animals $(C, D)$. Also, the border between striate and peristriate areas (marked by arrows) is sharp in both normal $(B)$ and anophthalmic $(D)$ animals.

\section{Materials and Methods}

Experimental procedures. Eight rhesus monkeys (four experimental and four age-matched controls) were used in the present study. The time of pregnancy, which in this species lasts $165 \mathrm{~d}$, was determined as described elsewhere (Rakic, 1972). Bilateral retinal ablation was performed in utero, at embryonic (E) day E60, E63, E67, or E81, as described by Rakic and Goldman-Rakic (1985). Following surgery, fetuses were returned to the uterus and the chorio-alantoic membranes, uterine, and abdominal wall were sutured. All animals were delivered at term. Three of the operated animals were sacrificed at the second postnatal month because previous studies indicated that the adult laminar, columnar, and areal pattern in the striate cortex in the macaque monkey is well established by that time (e.g., Hubel et al., 1977; Rakic, 1977a). In addition, the basic visual functions, including grating acuity, Vernier acuity, and color discrimination, are well developed by the end of the second month in this species (Teller and Boothe, 1979). The major neurotransmitter receptors in the macaque monkey display an elaborate adult pattern by that age, but the level of binding is higher than in the adult (Lidow et al., 1991a; Lidow and Rakic, 1992). One experimental animal in the present study was sacrificed at 1 year of age when receptor binding is fully differentiated (Lidow and Rakic, 1992). Therefore, the pattern of distribution, and in particular, the amount of binding for some radioligands at 2 months, may differ from that observed in the adult (Rakic et al., 1988; Lidow and Rakic, 1992). However, it should be underscored that, for the purpose of the present study, comparisons were made between operated and control groups based on animals sacrificed at 2 postnatal months.

Tissue preparation and binding assays. Animals were anesthetized with Na-pentobarbital $(40 \mathrm{mg} / \mathrm{kg}$ ) and perfused with ice-cold phosphatebuffered saline ( $\mathrm{pH} 7.4$ ) followed by $0.1 \%$ paraformaldehyde containing increasing concentrations of sucrose in buffered saline (Rakic et al., 1988). The light fixation allowed brain tissue to be sectioned more easily without affecting binding parameters (Rakic et al., 1988). The brains were rapidly removed, blocked, and immersed in isopentane at $-40^{\circ} \mathrm{C}$ for $5 \mathrm{~min}$ before storing at $-80^{\circ} \mathrm{C}$. Blocks of tissue containing striate and extrastriate cortex were cut in the coronal plane at $20 \mu \mathrm{m}$. Sections were mounted on acid-cleaned, chrom alum-subbed slides and kept at $-80^{\circ} \mathrm{C}$ until the time of assay, conducted no more than 2 weeks after tissue had been sectioned.

The protocols for the saturation binding assays used in this study have previously been described in Rakic et al. (1988) and Lidow et al. $(1989 \mathrm{a}, \mathrm{b})$ and are summarized in Table $1 .{ }^{3} \mathrm{H}$-prazosin was used to bind $\alpha 1$ adrenergic receptors. ${ }^{3} \mathrm{H}$-clonidine was employed to visualize high affinity $\alpha 2$ adrenergic receptors. ${ }^{125} \mathrm{I}$-pindolol was used to label $\beta$-ad- 

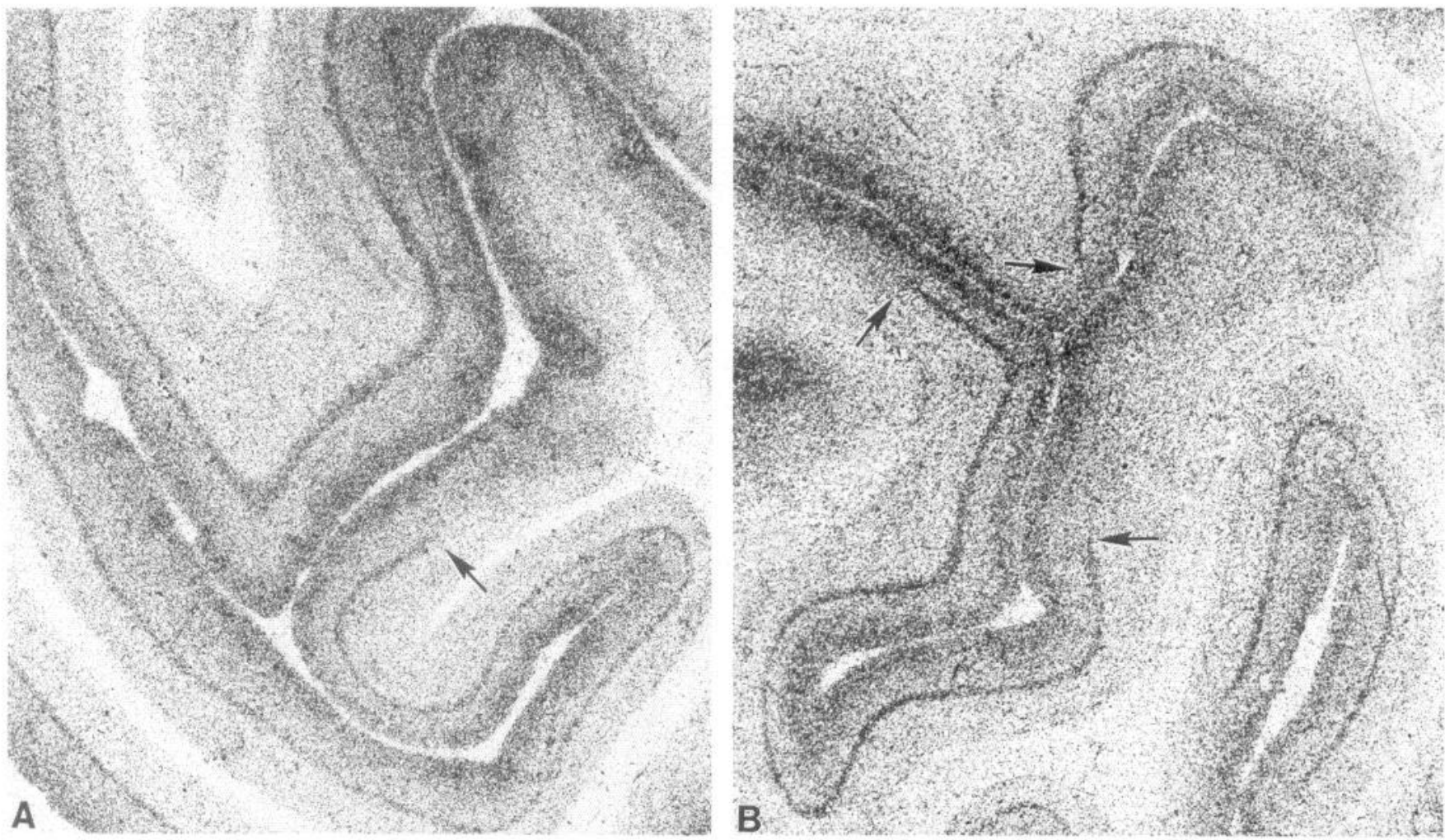

Figure 2. Typical labeling pattern of ${ }^{3} \mathrm{H}$-prazosin ( $\alpha 1$ adrenergic receptors) labeling in the visual cortex of normal $(A)$ and anophthalmic $(B)$ monkey, both 2 months old. Arrows indicate the border between striate and peristriate areas. Note the similarity in labeling pattern between the normal and experimental animal, except that in the anophthalmic animal, striate area is interrupted by a segment of cortex that resembles the peristriate area.

\section{$\left[{ }^{3} \mathrm{H}\right]$ prazosin}
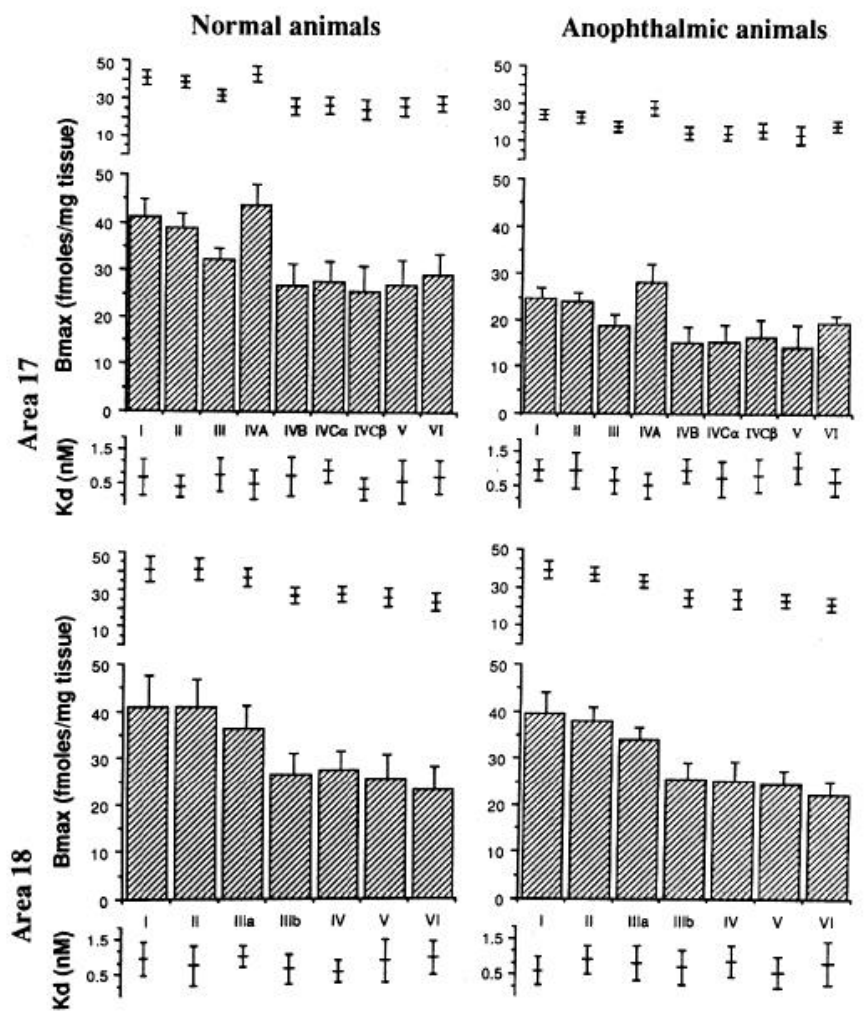

renergic sites. To prevent an inclusion of $5-\mathrm{HT}_{1}$-serotonergic receptors in the specific ${ }^{125}$ I-pindolol labeling, nonspecific binding for this radioligand was determined in the presence of an excess of isoproterenol. 5 - $\mathrm{HT}_{1}$-serotonergic sites were identified with ${ }^{3} \mathrm{H}$-hydroxytryptamine creatinine sulfate $\left({ }^{3} \mathrm{H}-5-\mathrm{HT}\right)$. Incubation buffer for ${ }^{3} \mathrm{H}-5-\mathrm{HT}$ binding contained fluoxetine to prevent binding to serotonin uptake sites, and pargyline to prevent the oxidation of the ligand by monoamine oxidase present in the tissue. ${ }^{3} \mathrm{H}$-ketanserin was used to label $5-\mathrm{HT}_{2}$-serotonergic receptors. The binding was done in the presence of prazosin to prevent radioligand binding to $\alpha 1$-adrenergic receptors. In addition, the use of methysergide as the displacing agent assures that the specific binding of ${ }^{3} \mathrm{H}$-ketanserin is not contaminated by $\alpha 1$-adrenergic, histamine, or unique ketanserin sites associated with dopaminergic terminals. ${ }^{3} \mathrm{H}-$ SCH23390 was employed to label $\mathrm{D}_{1}$-dopaminergic receptors. Labeling was done in the presence of mianserin to prevent radioligand binding to serotonergic and adrenergic sites. The last ligand used in this study

$\leftarrow$

Figure 3. Histograms representing the distribution of ${ }^{3} \mathrm{H}$-prazosin $(\alpha 1$ receptors) in visual cortex of 2-month-old control and anophthalmic animals. Three histograms are presented for the primary and secondary visual areas of both normal and experimental animals. The upper histogram shows $B_{\max }$ with $95 \%$ comparison intervals of Gabriel modification of GT2 test. The middle histogram presents the distribution of $B_{\max } \pm \operatorname{SEM}$ ( $n=3$ for each group). The lower histogram shows the distribution of $K_{d}$ with their comparison intervals. The roman numerals indicate cortical layers according to Lund (1988) except that sublayers IVC $\alpha$ and IVC $\beta$ are labeled IVC $\alpha$ and IVC $\beta$. If comparison intervals for any two $B_{\max }$ or $K_{d}$ overlap, there are no statistically significant differences between them. Note that while the pattern of ${ }^{3} \mathrm{H}$-prazosin labeling in both groups of animals is similar, the density of labeling in striate area of the experimental monkeys is significantly lower than in the controls. 

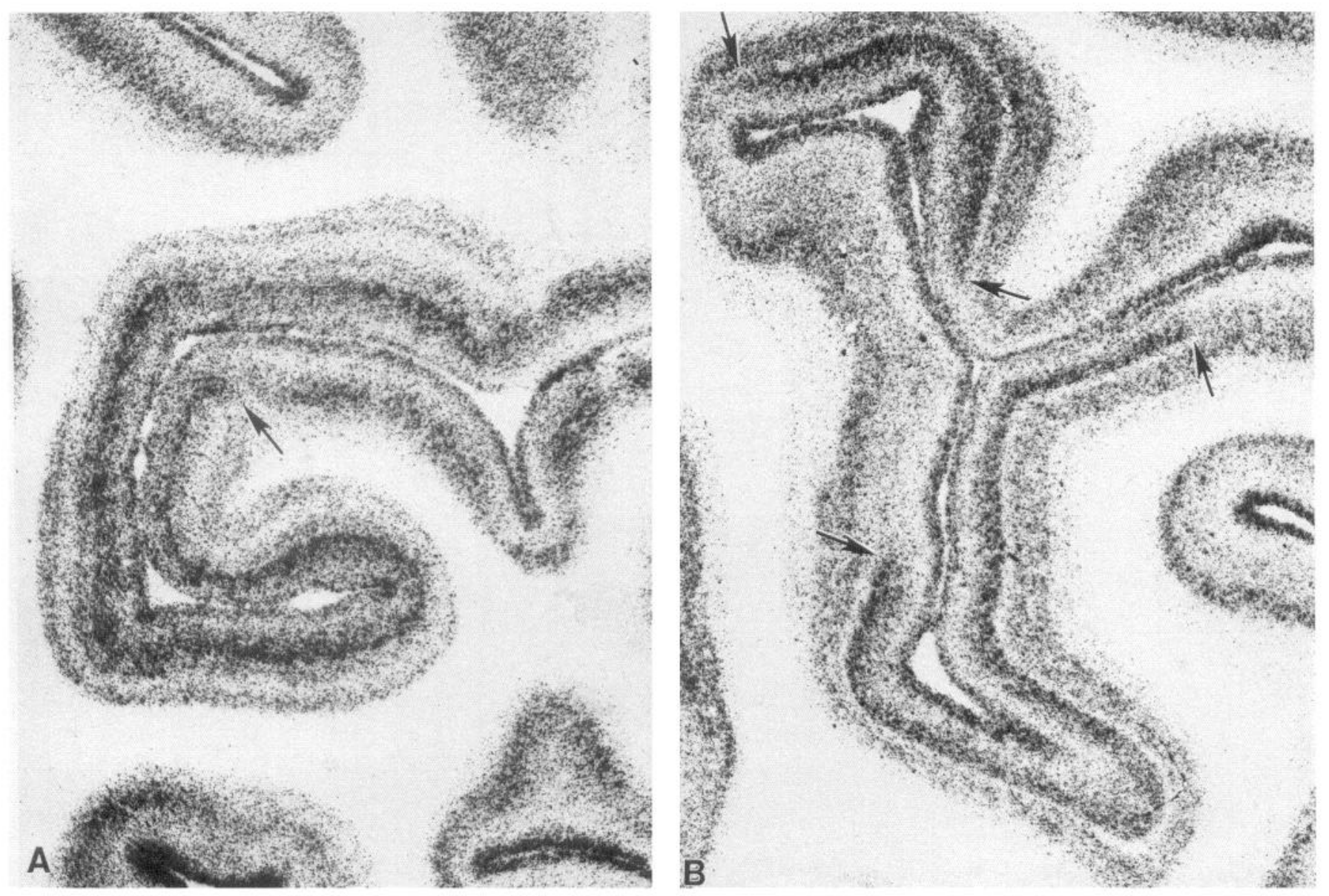

Figure 4. Typical labeling pattern of ${ }^{3} \mathrm{H}$-clonidine (high-affinity $\alpha 2$ receptors) labeling in the visual cortex of a normal (A) and an anophthalmic (B) monkey, both 2 months old. Arrows show the border between striate and peristriate areas. Note the similarity in labeling pattern between the normal and experimental animal. However, in the anophthalmic animal the striate area is interrupted by cortex that looks more as the peristriate area.

was ${ }^{3} \mathrm{H}$-spiperone. Originally, we expected it to allow us to visualize $\mathrm{D}_{2}$-dopaminergic receptors. However, we found later that under the conditions used in this study, ${ }^{3} \mathrm{H}$-spiperone binds receptor subtypes, which, in addition to $\mathrm{D}_{2}$ sites, include 5- $\mathrm{HT}_{2-}, 5-\mathrm{HT}_{1 \mathrm{~A}^{-}}, 5-\mathrm{HT}_{1 \mathrm{C}}$-serotonergic and $\alpha 2$-adrenergic sites (Lidow, et al., 1991b). Therefore, ${ }^{3} \mathrm{H}$-spiperone in the present study was used as the useful molecular probe for marking laminar and areal differences between anophthalmic and control animals rather than as the means to determine the precise distribution of functional $D_{2}$ receptor subtype, which can be labeled by more specific radioligand (Lidow et al., 1991b).

Quantitative densitometry. The identification of area 17 (striate cortex) and area 18 (peristriate cortex), as well as the definition of their lamination, was made according to the scheme of Brodmann (1909). The layers were identified according to the classification of Lund (1973). The autoradiograms were analyzed with a computer-imaging system described previously (Rakic et al., 1988). The system allows the overlay on a computer screen of the digitized images of cresyl violetstained sections and corresponding autoradiograms to identify histologically the autoradiographic image of each cortical layer and sublayer. In some instances, autoradiograms revealed that individual cytoarchitectonic layers can be further subdivided into two bands (e.g., layer IIIA and IIIB for ${ }^{3} \mathrm{H}$-clonidine or layer IVBa and IVBb for ${ }^{125} \mathrm{I}$-pindolol). The computer system also subtracts film images of sections with nonspecific binding from film images of adjacent sections with total binding, thus allowing the investigator to observe directly on the screen the images representing specific binding. The program then compares optical densities of film images of individual cortical layers with those of ${ }^{3} \mathrm{H}$ or ${ }^{125} \mathrm{I}$ standards, which were apposed to the film along with tissue sections. The optical densities from autoradiographs of labeled tissue were converted into concentrations of labeled compounds per tissue wet weight for each cortical layer. The diffuse optical densities used in this study were between 0.08 and 0.80 on all autoradiograms. Within this range, optical densities of ${ }^{3} \mathrm{H}$-sensitive ultrafilm are linearly related to variations in tissue radioactivity (Lidow et al., 1988).

The analysis of saturation binding utilized nonlinear, curve-fitting computer programs KINETIC/EDBA/LIGAND/LOWRY from Elsevier-BIOSOFT Co. (Cambridge, UK). The analyses were based on concentrations of radioactive ligands specifically bound to tissue labeled with five different concentrations of free ligands in incubating solutions. The number of data points employed for quantitative analysis of saturation binding is a compromise between the desired accuracy and the availability of appropriate tissue. Five concentrations of free ligand in incubating solution is a minimal number that allows a relatively accurate estimation of $B_{\max }$ and $K_{d}$ for a one-site receptor model (Brooksbank et al., 1978; Lidow et al., 1989a). $B_{\max }$ and $K_{d}$ values obtained from different layers of each neocortical area were compared with Gabriel's modification of the GT2-method (Sokal and Rohlf, 1981). This method utilizes the data provided by KINETIC/EDBA/LIGAND/LOWRY and produces $95 \%$ comparison intervals for each $K_{d}$ or $B_{\max }, K_{d}$ or $B_{\max }$ with overlapping intervals considered statistically identical; $K_{d}$ or $B_{\max }$ with intervals that do not overlap are considered statistically different. Plots of these comparison intervals make it very easy to appreciate the degree of variation in $K_{d}$ or $B_{\max }$ within each cortical area as well as to identify the layers for which these variations are statistically significant. For most ligands, binding was repeated on three experimental and three control animals of 2 months of age. However, in the case of ${ }^{3} \mathrm{H}$ $\mathrm{SCH} 23390$ and ${ }^{125} \mathrm{I}$-pindolol, the ligands were introduced late in the study. Thus, binding of ${ }^{3} \mathrm{H}-\mathrm{SCH} 23390$ was conducted on only one experimental and one control animal of 2 months of age. In the case of ${ }^{125} \mathrm{I}$-pindolol, the quantitative data were obtained only from the animals 
$\left[{ }^{3} \mathrm{H}\right]$ clonidine
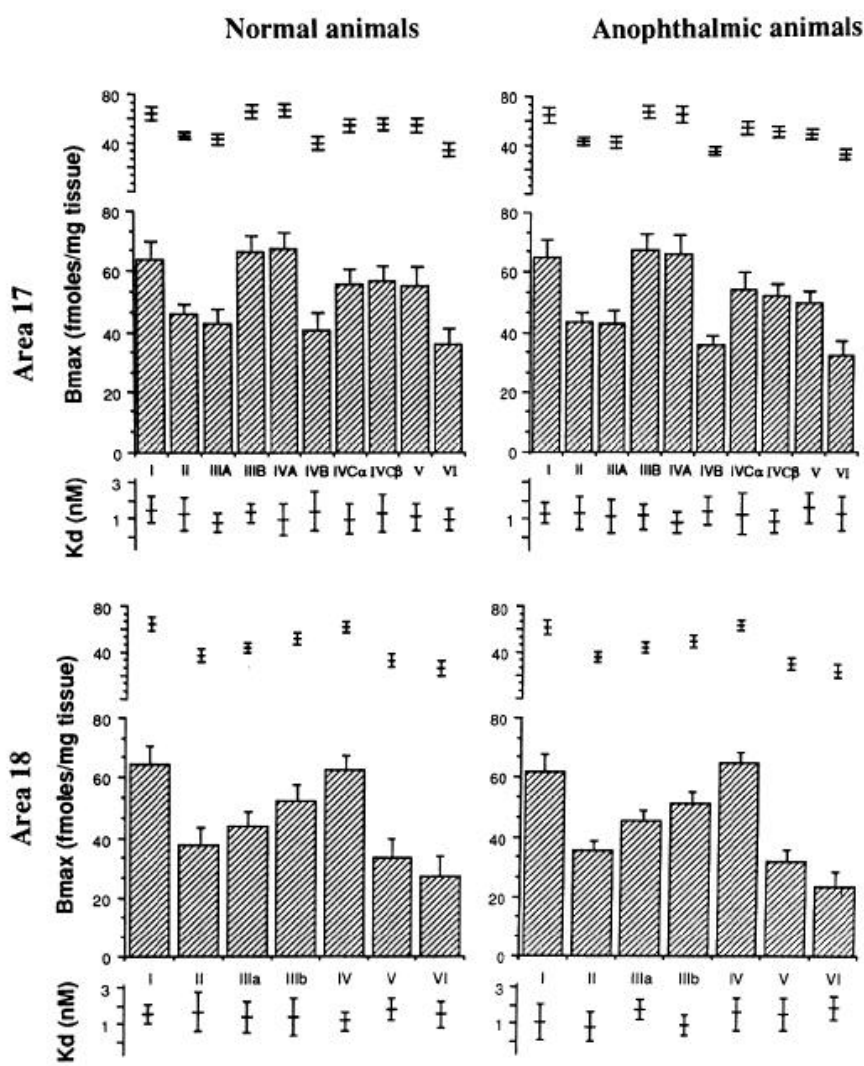

Figure 5. Histograms representing the distribution of ${ }^{3} \mathrm{H}$-clonidine (high-affinity $\alpha 2$ receptors) in visual cortex of control and anophthalmic 2 -month-old monkeys. Conventions are the same as in Figure 3. Note the similarity in both density and distribution of ${ }^{3} \mathrm{H}$-clonidine labeling in both groups of animals.

of 1 year of age. Two-month-old animals provided qualitative data for this radioligand.

Quenching correction for ${ }^{3} \mathrm{H}$-generated autoradiographic images of layer IVB in the striate cortex was made as described earlier (Lidow et al., 1988). The measurements obtained from 2-month-old animals were not corrected for quenching since no significant amount of myelin is developed by that time in layer IVB (see Lidow and Rakic, 1992, their Fig. 1).

\section{Results}

Cytoarchitectonic pattern. The surface of the occipital lobe in all anophthalmic animals was more convoluted than in the controls and commonly contained a deep horizontal sulcus running across the occipital operculum (Rakic, 1988). The striate cortex (area 17) and the adjacent peristriate cortex (area 18) were, in each case, first identified in cresyl violet-stained preparations (Fig. 1). In agreement with previous observations (Rakic, 1988), the striate area in the prenatally enucleated animals could be recognized by its characteristic cytoarchitectonic laminar pattern. In particular, one can easily distinguish sublayers IVA, IVB, IVC $\alpha$, and IVC $\beta$ that reveal the segregation of the $\mathrm{M}$ and $\mathrm{P}$ system in the cortex. The thickness of each layer was approximately equal to that of the age-matched controls, except for layer I, which was usually $10-15 \%$ wider than in the control. The border of the striate cortex with adjacent areas was always very sharp and easily discernible. A cursory examination of the tissue sections also revealed that the surface of the striate area in the early enucleates was significantly smaller
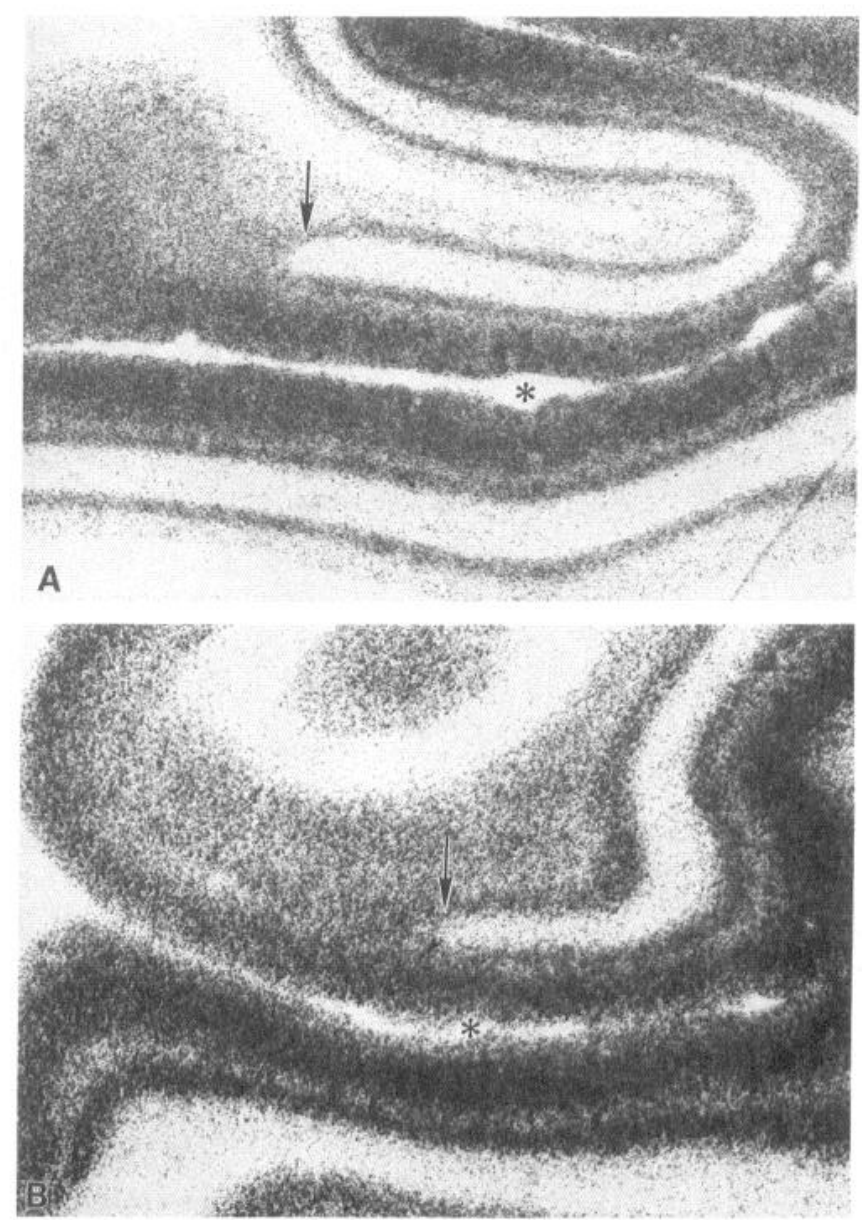

Figure 6. Typical labeling pattern of ${ }^{125} \mathrm{I}$-pindolol ( $\beta$ receptors) in the visual cortex of normal $(A)$ and anophthalmic $(B)$ 1-year-old monkeys. The cortex in both photographs is represented twice, once above and once below the calcarine fissure (asterisks). Arrows indicate the sharp border between striate and peristriate areas in the upper lip of the fissure. The photographs illustrate the similarity in labeling laminar pattern in the normal and experimental animals, although layer VI in $B$ is cut tangentially due to the development of more elaborate convolutions in the anophthalmics.

than the surface occupied by this area in control animals. In some specimens, the striate area appears to be barely one-third of the normal size in both surface and number of nerve cells. This dramatic decrease in the size of the striate area is in agreement with our quantitative analysis based on the frozen and celloidin-embedded, cresyl violet-stained serial sections (Rakic, 1988; Rakic et al., 1991; I. Suner and P. Rakic, unpublished observation). The division of the peristriate cortex into areas 18, 19, or unusual archetype (area X of Rakic et al., 1991) was more difficult to assess. The light fixation of the tissue, required for receptor autoradiography, did not allow sufficient resolution to delineate these areas on cresyl violet sections and no variations in the receptor binding patterns within prestriate cortex were recorded for any of radioligands used in this study. Thus, we concentrated the present analysis on the striate cortex and refer to the regions outside its border in the occipital lobe as the peristriate area.

${ }^{3} \mathrm{H}$-prazosin binding. The $\alpha 1$-specific binding of ${ }^{3} \mathrm{H}$-prazosin had a similar distribution in both 2-month-old prenatally operated animals and age-matched normal controls. In the striate area 

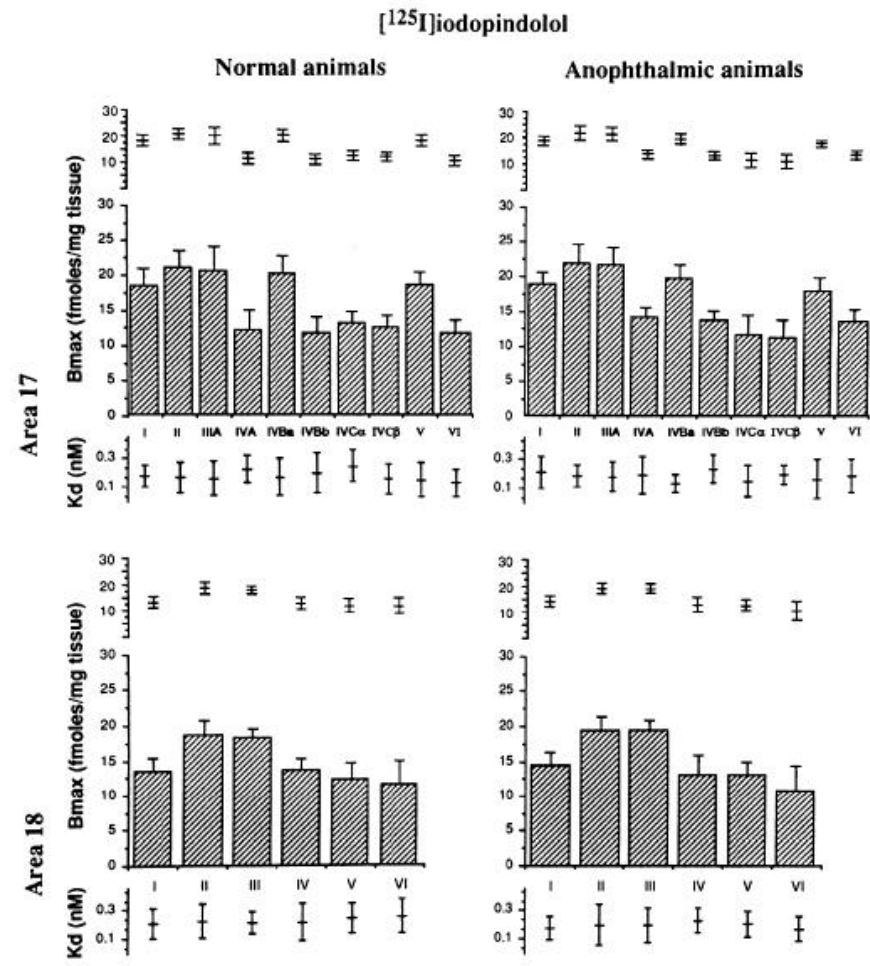

Figure 7. Histograms representing the distribution of ${ }^{125} \mathrm{I}$-pindolol $(\beta$ receptors) in visual cortex in the 1-year-old control and anophthalmic animals. Conventions are as in Figure 3. For this particular ligand, the data were collected from a single normal and experimental animal, both of which display the similarity in the distribution of ${ }^{125} \mathrm{I}$-pindolol binding.

of all specimens, the pattern of binding was characterized by the two additional darker bands-one thin, densely labeled and associated with sublayer IVA and the other much less dense corresponding to layer VI (Fig. 2). Although it is difficult to discern in the individual photograph, a medium-dense band is present in layer VI, which is confirmed by densitometry (see below). While the superficial, broad band in layers I and II continues over the entire occipital surface, the dark bands corresponding to deeper layers are present only in the striate area. The border of the striate and peristriate cortex can be easily discerned as the site where the dark bands corresponding to layers IVA and VI abruptly disappear (Fig. 2A,B). However, in contrast to the binding in normal tissue, the striate pattern of ${ }^{3} \mathrm{H}$-prazosin binding in the depth of the calcarine fissure of the enucleated animals was often interrupted by the inserts of segments with a pattern of receptor binding similar to that of the peristriate cortex (Fig. $2 B$ ). Since only 20 sections were used for the binding of this ligand in each case, we could not determine whether the segment displaying this deviation from the characteristic striate pattern of binding represents an "island" encircled by the normal-looking cortex or a "peninsula" that is anteriorly continuous with the adjacent area.

Histograms of the $B_{\max }$ values of ${ }^{3} \mathrm{H}$-prazosin binding across cortical layers in normal and enucleated animals confirmed quantitatively the visual impression of the similarity in the pattern of laminar distribution of this radioligand in the striate cortex in both groups of animals (Fig. 3). The highest level of binding in IVA of the striate cortex is evident in all animals, as is the small, statistically nonsignificant increase in layer VI. However, although the laminar pattern was remarkably similar
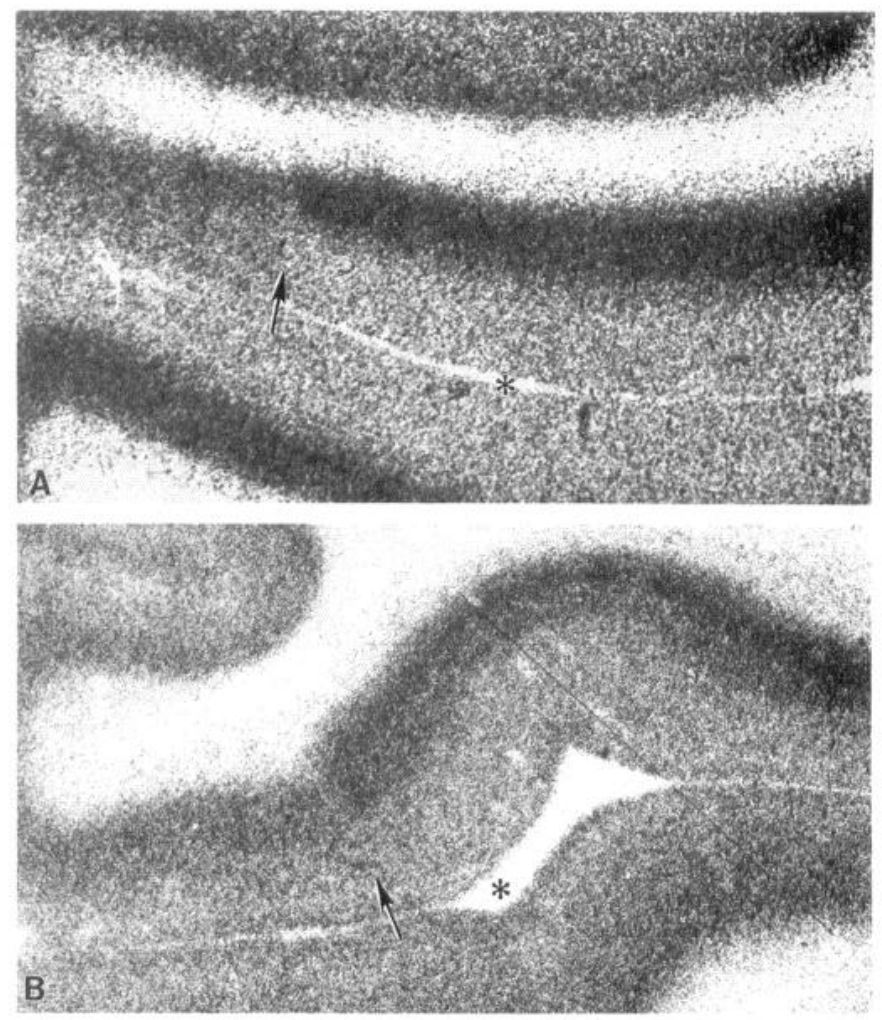

Figure 8. Typical labeling pattern of ${ }^{3} \mathrm{H}-5-\mathrm{HT}\left(5-\mathrm{HT}_{1}\right.$ receptors) in the visual cortex of a normal $(A)$ and an anophthalmic $(B)$ monkey, both 2 months old. Note that the cortex is represented twice, above and below the calcarine fissure (asterisks). The band of heavily labeled deep layers in the striate cortex in the upper lip of the sulcus stops abruptly at the border to peristriate cortex in both specimens (arrows). Labeling pattern of both area in the normal and experimental animal is similar.

in both groups of animals, the density of binding was consistently $35-40 \%$ lower in the experimental group compared to the normal controls (Fig. 3). This reduction was proportional in all cortical layers, so that the overall pattern of receptor distribution remained preserved. In addition, there were no differences in the affinity of this radioligand between control and experimental tissues (Fig. 3).

${ }^{3} \mathrm{H}$-clonidine binding. The $\alpha 2$-specific labeling of ${ }^{3} \mathrm{H}$-clonidine in the striate cortex of normal 2-month-old monkeys displayed three dark bands (Fig. 4A). The superficial band corresponded to layer I. The domain of the middle band included layers IIIB and IVA, while the deepest situated band corresponded to cytoarchitectonic layers IVC and V (Fig. 4A). The same three-layer pattern was observed in the 2-month-old animals enucleated as fetuses between E60 and E67 (Fig. 4B). The border of the striate to peristriate area in both groups of animals was easily recognizable by the abrupt loss of the dense band present corresponding to layers IIIB/IVA. However, the higher levels of binding present in layers I, IVC $\beta$ and V of the striate cortex continued without interruption across the border into layers I, IV and V of the peristriate area. As in the case of ${ }^{3} \mathrm{H}$-prazosin binding, ${ }^{3} \mathrm{H}$ clonidine binding across the anterior portion of calcarine fissure of anophthalmic specimens showed a short segment of the extrastriate pattern (Fig. 4B), which was not present in agematched controls (Fig. 4A). However, again due to the gap in serial sections, we could not determine whether this segment represents an isolated "island" or a "peninsula." 
$\left[{ }^{3} \mathrm{H}\right] 5-\mathrm{HT}$
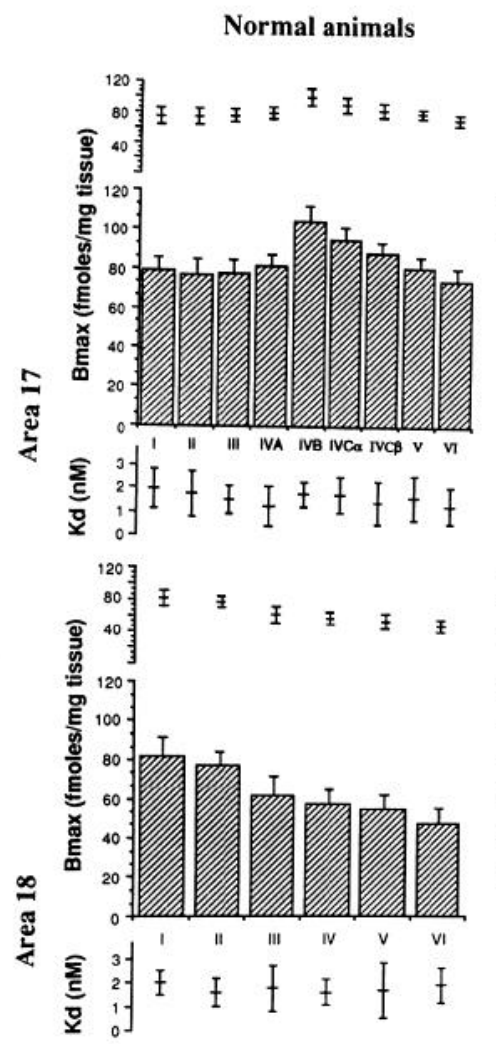

Anophthalmic animals
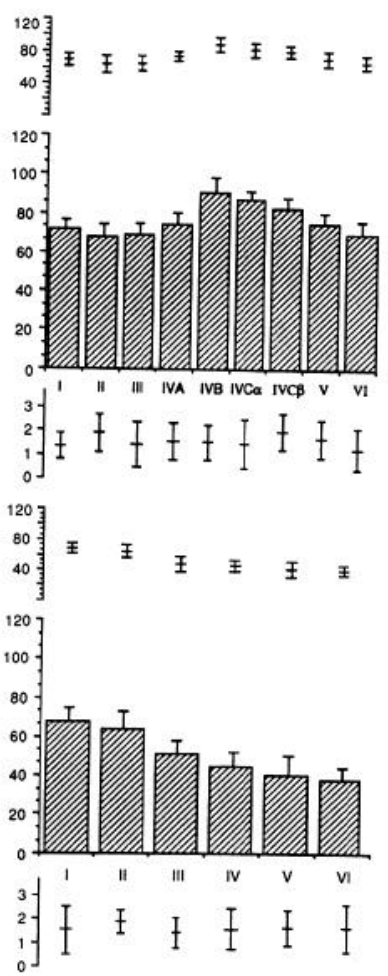

Figure 9. Histograms representing the distribution of ${ }^{3} \mathrm{H}-5-\mathrm{HT}\left(5-\mathrm{HT}_{1}\right.$ receptors) in the visual cortex of control and anophthalmic 2-month-old monkeys. Conventions are as in Figure 3. Note the similarity of both density and distribution on ${ }^{3} \mathrm{H}-5-\mathrm{HT}$ labeling in both groups of animals.

The $B_{\max }$ values for ${ }^{3} \mathrm{H}$-clonidine were similar in control and experimental groups across all layers in both striate and peristriate cortex (Fig. 5). However, unlike $\alpha 1$ receptor, $\alpha 2$ sites display a high density in cell-sparse layer I that is similar to the more cellular layers IIIb, IVA. Furthermore, no difference in $K_{d}$ values could be discerned between enucleates and control in any of the layers (Fig. 5).

${ }^{125} \mathrm{I}$-pindolol binding. ${ }^{125} \mathrm{I}$-pindolol was used for analysis of the distribution of $\beta$-adrenergic receptors. In the striate cortex of normal 1-year-old animals, the binding of this radioligand was characterized by a prominently high density in layers I, II, III, the superficial half of IVB and V and low density in sublayers IVA, the deep half of IVB and IVC (Fig. 6A). The high binding density in the superficial half of layers IVB and $\mathrm{V}$ as well as low density in sublayers IVA, the deep half of IVB, and IVC stopped abruptly at the border of the striate area. However, the binding density in superficial layers I, II, and III continued into the prestriate cortex (Fig. 6A). The same laminar pattern as well as an abrupt change at the areal border was present in the operated animals. Comparison of the photographs in Figure $6, A$ and $B$, shows a remarkable similarity in the laminar composition between operated and controls, although the oblique cut, due to the more elaborate convolutions in anophthalmics, renders layer VI as distorted and wider than it is (Fig. 6B). Particularly dramatic is abrupt stop of the low-density band the striate/peristriate border in both specimens.

$B_{\max }$ values of ${ }^{125} \mathrm{I}$-pindolol binding in all layers in the striate and peristriate areas were basically indistinguishable between

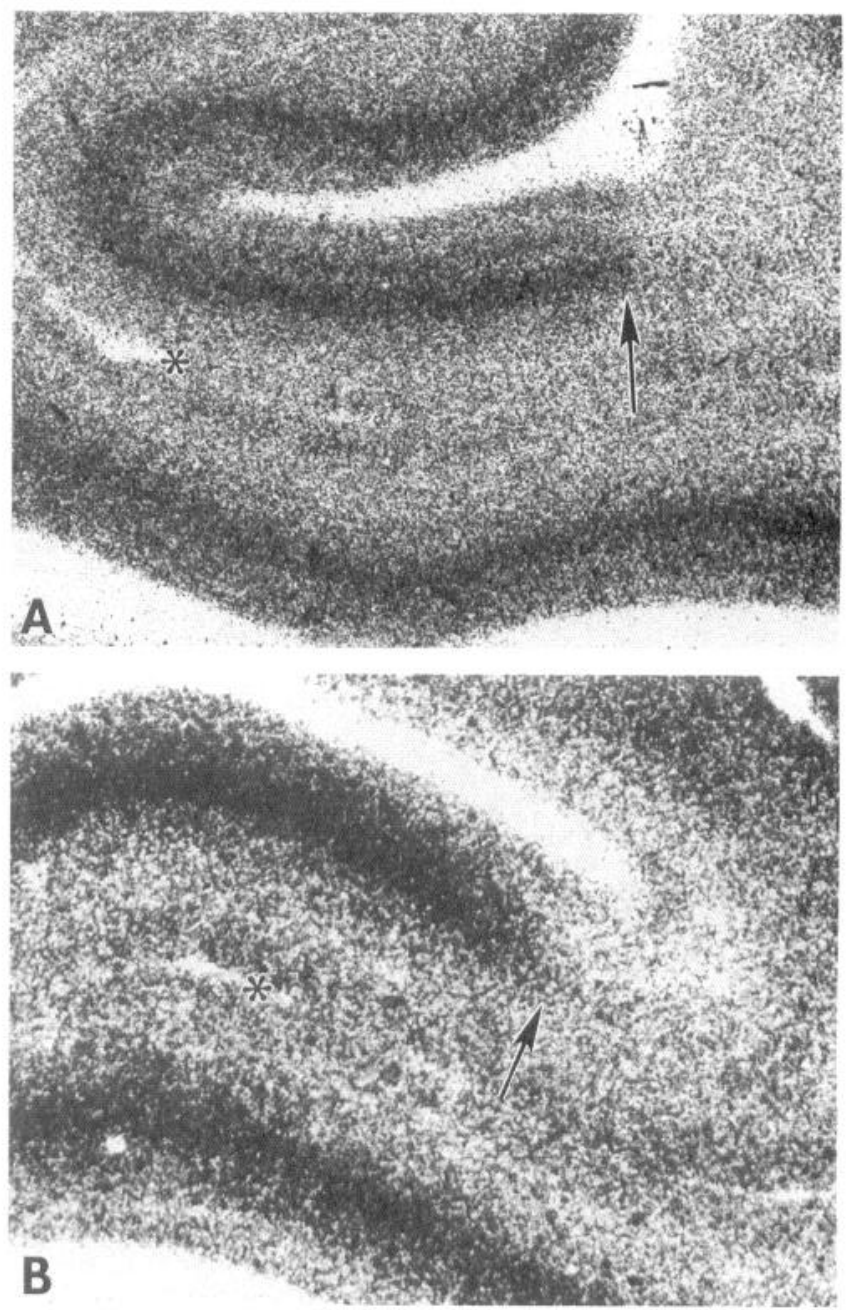

Figure 10. Typical labeling pattern of ${ }^{3} \mathrm{H}-$ ketanserin $\left(5-\mathrm{HT}_{2}\right.$ receptors) in the visual cortex of a normal $(A)$ and an anophthalmic $(B)$ monkey, both 2 months old. The calcarine fissure is marked with asterisk. Arrows point to the border between striate and peristriate areas, which is visible due to the relatively abrupt disappearance of heavy label in the deep cortical layers. Despite the change in position of the border, the laminar pattern of labeling is similar in both specimens.

the two groups of animals (Fig. 7). There were no differences in $K_{d}$ values (Fig. 7). While we had only a limited number of tissue sections from 2-month-old animals labeled with ${ }^{125}$ I-pindolol, they showed similar patterns of labeling in experimental and control animals (not shown).

${ }^{3} \mathrm{H}-5-\mathrm{HT}$ binding. In the striate area of normal 2-month-old specimens, 5- $\mathrm{HT}_{1}$ specific binding of ${ }^{3} \mathrm{H}-5-\mathrm{HT}$ had a dark band in layer IVB, which merges with a more moderate binding in IVC. The borderline of striate and prestriate areas was sharply delineated; radiolabeling of layer IV is much lighter in the peristriate area (on the left side in Fig. 8A). Similarly, the sharp border and the same areal and laminar pattern can be observed in the enucleated 2-month-old animals (Fig. 8B). Quantitative analysis revealed a similar laminar distribution and densities of ${ }^{3} \mathrm{H}-5$-HT binding in both areas (Fig. 9). There were no differences in affinity of ${ }^{3} \mathrm{H}-5$-HT binding in the two groups of animals (Fig. 9).

${ }^{3} \mathrm{H}$-ketanserin binding. $5-\mathrm{HT}_{2}-$ specific binding of ${ }^{3} \mathrm{H}$-ketanserin was particularly high in layers IVB, IVC, and V in the 


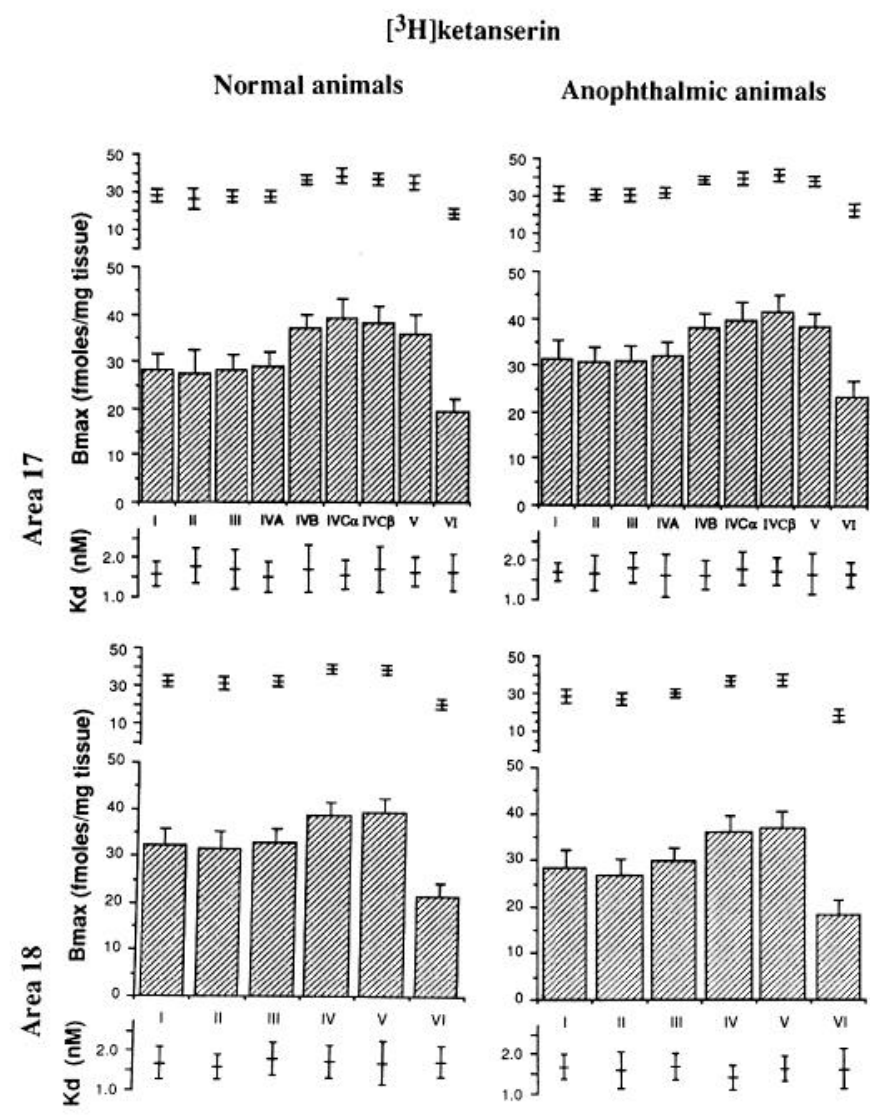

Figure 11. Histograms representing the distribution of ${ }^{3} \mathrm{H}$-ketanserin (5- $\mathrm{HT}_{2}$ receptors) in the visual cortex of control and anophthalmic animals 2 months old display similarity in binding pattern. Conventions are as in Figure 3.

striate areas of the normal 2-month-old monkeys. Although the same set of layers (IV and V) were also intensely labeled in the peristriate area, here the intensity of labeling was visibly lower than in area 17, making the areal border easily recognizable (arrow in Fig. 10A). An essentially similar pattern was observed in the operated animals (Fig. 10B). Quantitative analysis showed no differences in $B_{\max }$ and $K_{d}$ values between experimental and control animals (Fig. 11).

${ }^{3} \mathrm{H}$-SCH23390 binding. In the striate cortex of the 2-monthold monkey, the $\mathrm{D}_{1}$-specific ${ }^{3} \mathrm{H}-\mathrm{SCH} 23390$ binding had three dark, high-density bands corresponding to layers I, II, IVB and V, VI, respectively (Fig. 12A). Only the middle band, localized to layer IVB, disappeared abruptly at the border to the peristriate area. This change in binding pattern, nevertheless, makes a clear demarcation marker for identification of the areal border (Fig. $12 B$ ). Essentially the same findings were obtained for both cytoarchitectonic areas in the operated and age-matched control animals.

The quantitative analysis of autoradiograms supported our visual observation that ${ }^{3} \mathrm{H}-\mathrm{SCH} 23390$ had a similar pattern of labeling in both experimental and control groups of animals. However, the $B_{\max }$ values for this ligand in all layers of both striate and peristriate areas of the experimental specimens were about $15 \%$ higher than in the control (Fig. 13). It should be underscored that, as we mentioned in the Materials and Methods, only one experimental and one control animal were processed for the analysis of this particular ligand. This fact may raise some un-
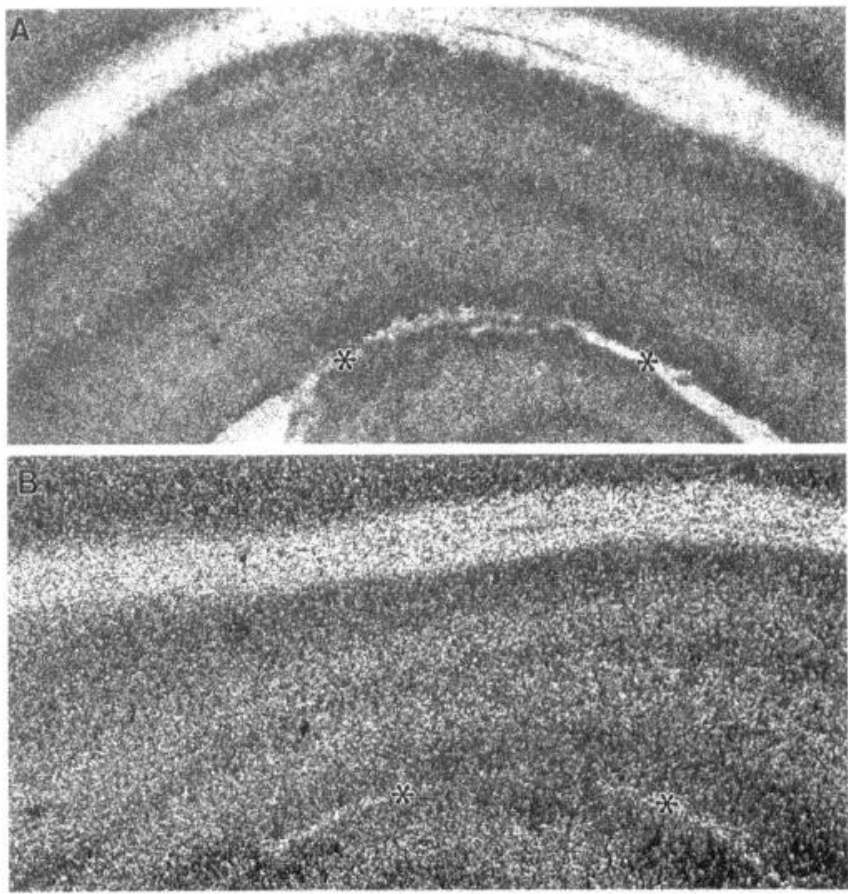

Figure 12. Typical labeling pattern of ${ }^{3} \mathrm{H}-\mathrm{SCH} 23390$ (D $\mathrm{D}_{1}$ receptors) in the striate visual cortex of a normal $(A)$ and an anophthalmic $(B)$ monkey, both 2 months old. Note the similarity in labeling pattern between the normal and experimental animals.

certainty concerning the validity of the $B_{\max }$ values given for ${ }^{3} \mathrm{H}$ $\mathrm{SCH} 23390$.

${ }^{3} \mathrm{H}$-spiperone binding. The labeling of ${ }^{3} \mathrm{H}$-spiperone in the striate cortex of the normal 2-month-old monkeys was characterized by a wide dark band corresponding to layers IVC and V, which stops at the border with the peristriate areas (Fig. 14A). In the latter cortical region, the labeling was largely homogeneous (Fig. $14 A$ ). The distribution of the ${ }^{3} \mathrm{H}$-spiperone was similar between the normal and enucleated monkeys in both cytoarchitectonic areas examined (Fig. 14B). The $B_{\max }$ and $K_{d}$ values for all layers in both areas were similar in all specimens (Fig. 15).

\section{Discussion}

The distinct difference in neuronal organization between striate and peristriate areas in primates develops as a result of synergistic interactions between the intrinsic capacity of cortical cells and information from the periphery via thalamocortical connections (Rakic, 1988, 1991; Rakic et al., 1991; Kennedy and Dehay, 1993). The present study adds to the growing list of molecular and cellular features of the cerebral cortex that can develop and be maintained independently of modality-specific cues originated in the peripheral receptors and transferred to the cortical neurons via thalamocortical pathways (Berry and Hollingsworth, 1973; Kaiserman-Abramov et al., 1983; Dehay et al., 1989; Kuljis and Rakic, 1989; Kennedy et al., 1990; Rakic et al., 1991; Arimatsu et al., 1992; Barbe and Levitt, 1993; Ferri and Levitt, 1993; Kind et al., 1993; Cohen-Tannoudji et al., 1994; Schlaggar et al., 1994). However, to evaluate the developmental significance of the present findings, one has to take into account the embryonic stage when enucleation has been performed.

The timing of enucleation. Retinal ablation was performed 


\section{$\left[{ }^{3} \mathrm{H}\right] \mathrm{SCH} 23390$}
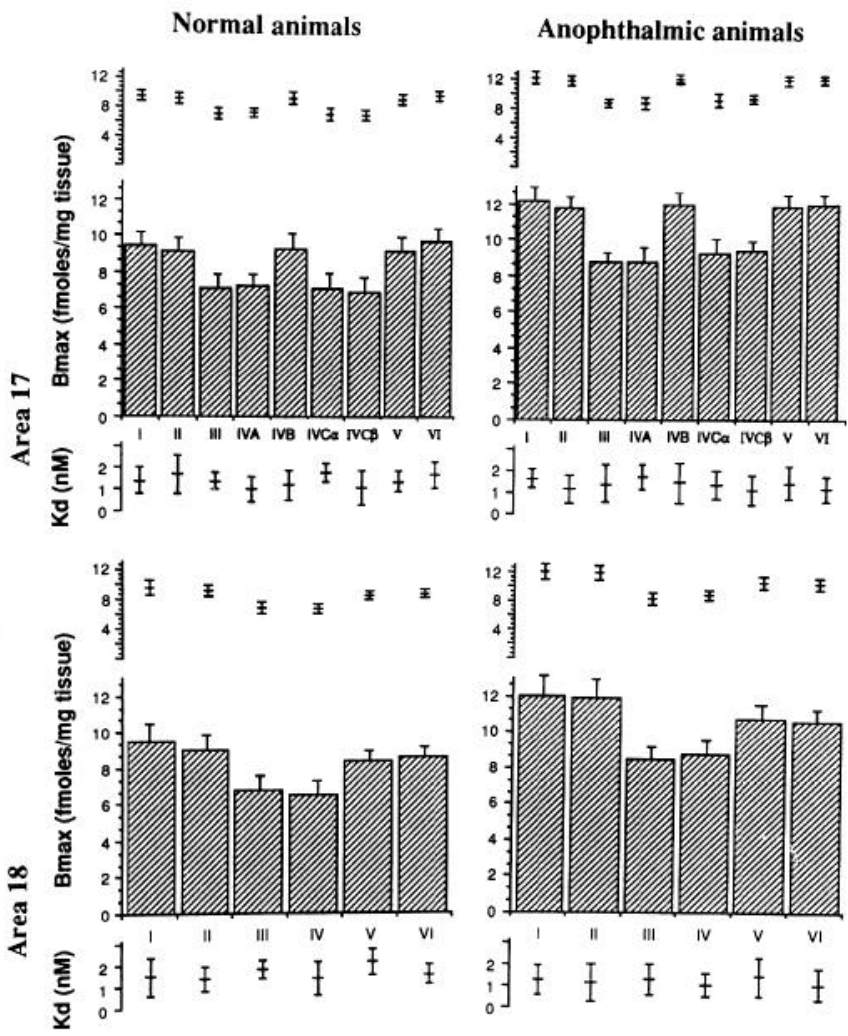

Figure 13. Histograms representing the distribution of ${ }^{3} \mathrm{H}-\mathrm{SCH} 23390$ $\left(D_{1}\right.$ receptors) in the visual cortex of the 2-month-old control and anophthalmic animals. Conventions are as in Figure 3. Note the similarity on distribution of ${ }^{3} \mathrm{H}$-clonidine labeling in both animals. However, although the pattern of ${ }^{3} \mathrm{H}-\mathrm{SCH} 23390$ labeling in both animals is the same, the density of labeling in the experimental monkey is significantly higher than in the control.

during the first half of the $165 \mathrm{~d}$ gestation of the macaque monkey. At the beginning of that time (E60, E63, E67 specimens), less than one-third of the photoreceptors and only about half of the retinal ganglion cells have been generated (LaVail et al., 1991). At the end of this period (E81) the genesis of ganglion cells has been completed, but, importantly, synaptic contacts between photoreceptors and ganglion cells via bipolar cells have not been established (Nishimura and Rakic, 1985). The mosaic map of rods and three wave-length sensitive cones has not emerged at the time of enucleation (Wikler and Rakic, 1991, 1994). Although all neurons destined for the lateral geniculate nucleus have been generated at the time of enucleation in the youngest three specimens (Rakic, 1977b), only the infragranular layers in the visual cortex have been formed (Rakic, 1974). Therefore, neurons of layer IV, the main recipient of thalamic input, as well as layers III and II, are generated only after the animals have been enucleated. At the time of early enucleation, some ganglion cells have extended their axons to the lateral geniculate nucleus (Rakic and Riley, 1983; Williams et al., 1991), but did not as yet form synapses (Hendrickson and Rakic, 1977). Although some geniculate axons already have invaded the wall of telencephalic vesicle (Rakic, 1976), they are suspended in the transient subplate zone and have not entered the cortical plate itself (Rakic, 1977a). Therefore, at the time of enucleation there is an early axonal link between the retinal gan-

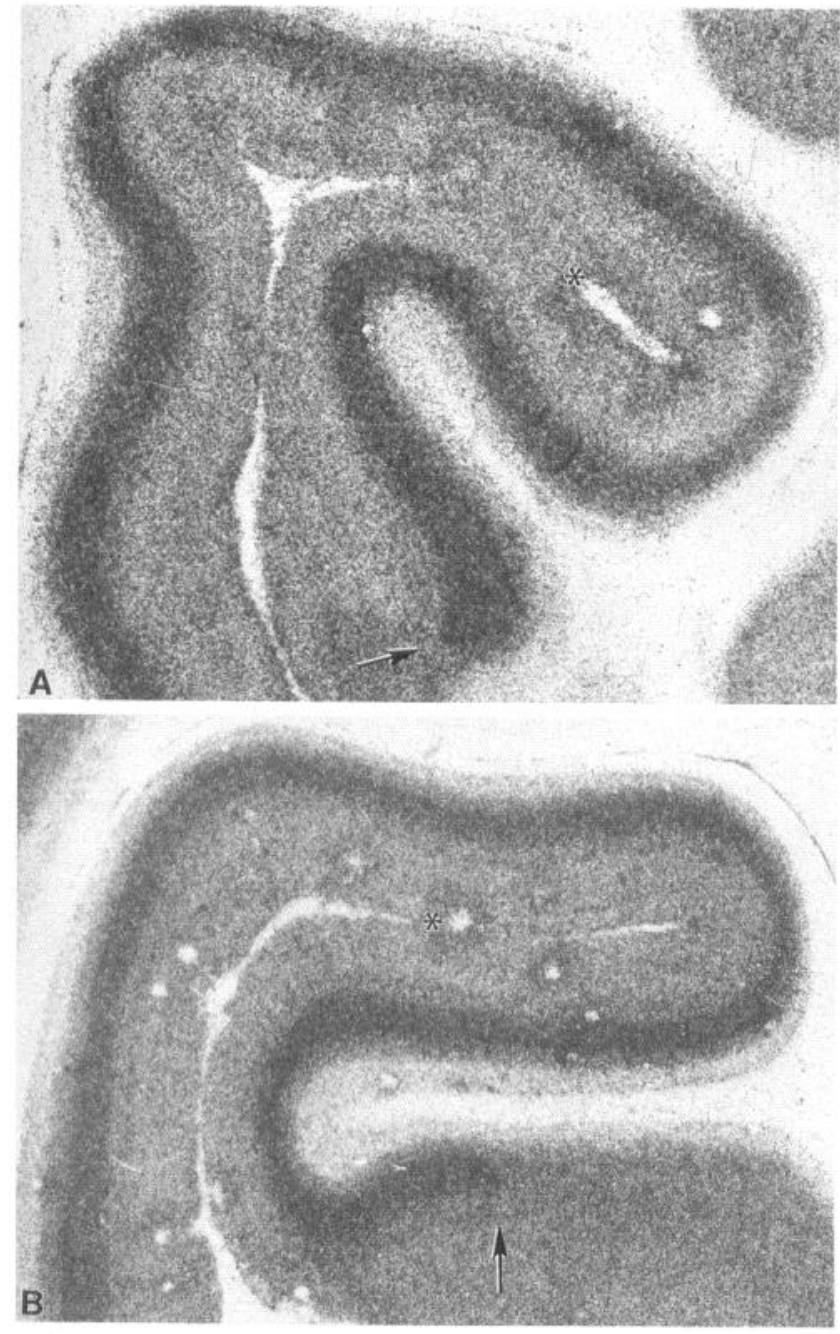

Figure 14. Pattern of ${ }^{3} \mathrm{H}$-spiperone labeling in the visual cortex of a normal $(A)$ and an anophthalmic $(B)$ monkey, both 2 months old, shows similarity. Arrows indicate the border between striate and peristriate areas.

glion cells and the diencephalon, but, importantly, the photoreceptors are not connected to the ganglion cells, synaptic contacts in the primary visual pathway have not been established, and layer IV, the main recipient of the geniculate input, has not been generated yet.

Bilateral enucleation performed during the first half of gestation of the macaque monkey results in a significant reduction in size of the lateral geniculate nucleus (Rakic, 1988; Dehay et al., 1989). The nucleus develops neither the layers nor the magno- and parvocellular division that normally comprise a relay station in the $\mathrm{M}$ and $\mathrm{P}$ system (see introductory remarks). The geniculate nucleus retains only 400,000 and 800,000 neurons from over 2,000,000 (Williams and Rakic, 1988) present when the surgery was performed, around E60 and E80, respectively (Rakic et al., 1991; Suner and Rakic, unpublished observation). Therefore, in the present study, the developing visual cortex was deprived of all information from the retina, and could receive only partial, presumably undifferentiated information from the grossly diminished lateral geniculate nucleus that did not segregate into $\mathrm{M}$ and $\mathrm{P}$ layers. These facts should be taken into account in the interpretation of monoamine receptor develop- 


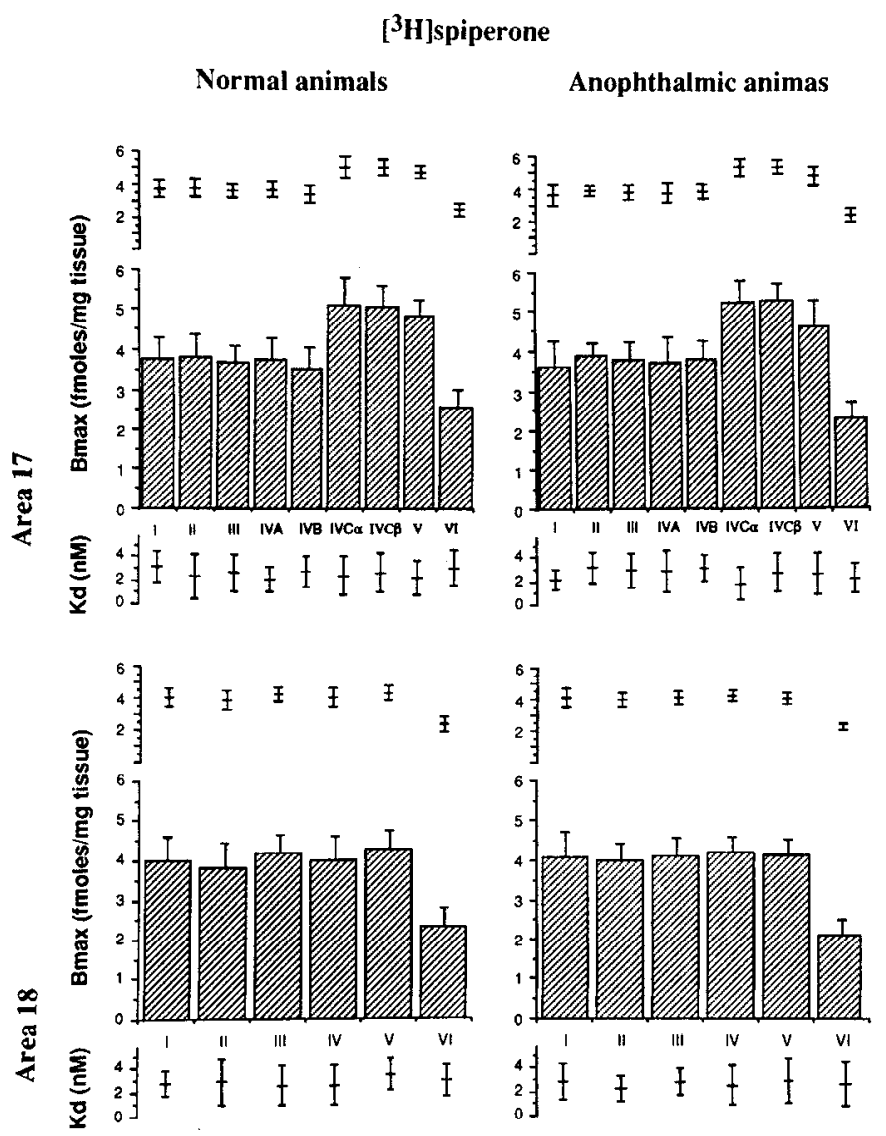

Figure 15. Histograms representing the distribution of ${ }^{3} \mathrm{H}$-spiperone in visual cortex of control and anophthalmic 2-month-old monkeys. Nonspecific binding was determined in the presence of an excess of (+)butaclomol. Conventions are as in Figure 3. Note the similarity of both density and distribution on ${ }^{3} \mathrm{H}$-spiperone labeling in both groups of animals.

ment and distribution in the cortex of prenatally induced anophthalmia.

Distribution of monoaminergic receptors in the anophthalmic animals. As has been shown in previous primate studies involving prenatal binocular enucleation, the basic cytoarchitectonic features, including lamination of the visual cortex, were relatively well preserved, although the size of the striate area was significantly smaller than in the age-matched controls (Rakic, 1988; Dehay et al., 1989; Rakic et al., 1991; Suner and Rakic, unpublished observation). In addition, the present analysis showed that all seven monoamine receptor subtype-specific radioligands examined display a normal pattern of distribution in anophthalmics. Five radioligands had the same density as in the controls, and only two receptor subtypes displayed a statistically significant difference in their concentration, as expressed in $B_{\max }$ values. For example, although the density of $\alpha 1$-labeling with ${ }^{3} \mathrm{H}$-prazosin in anophthalmics was lower than in the controls, the pattern of labeling was nevertheless remarkably similar to in both groups of animals. Since the lower density of binding can be attributed to the total absence of visual stimulation from the retina, the initial formation of the normal laminar pattern, characteristic for the striate cortex, in the absence of this stimulation from the carly cmbryonic stages is even more significant. In particular, we find intriguing that normally high $\alpha 2$-specific binding of ${ }^{3} \mathrm{H}$-clonidine in sublayers IVA and IVC $\beta$ (Rakic et al., 1988) was present also in the cortex of anophthalmic ani- mals. Since these sublayers normally receive input from the color opponent $\mathrm{P}$ system all the way from the retina via the parvocellular layer of the lateral geniculate body (see introductory remarks), the present results in the anophthalmic animals indicate that the density of $\alpha 2$-adrenergic receptors and their high distribution in cortical sublayers subserving color vision are not induced and/or maintained by impulse activity or some other information from the wavelength-sensitive photoreceptors. Thus, unlike the formation of ocular dominance columns, which are induced by competition between inputs subserving two eyes (Rakic, 1976; Hubel et al., 1977), the segregation of cortical layers devoted to color and noncolor visual functions can form in the absence of activity pattern originated in the retina. For example, removal or even occlusion of a single eye prevents formation of the ocular dominance columns (Hubel et al., 1977; Rakic, 1981), suggesting that activity-dependent binocular competition, initiated from the retina, is an essential factor (Shatz, 1990). The present results, as well as the nearly normal development of cytochrome oxidase patches in prenatally bienucleatcd animals (Kuljis and Rakic, 1989), indicate that their cytoand chemoarchitectonic features can form independently of the activity pattern in the retina.

While the role of signals originated from the retinal photoreceptors on the distribution of any of the ligands tested in the present study can be excluded, it is not possible to determine what role, if any, geniculocortical input may play in this process. In macaque monkey fetus, adrenergic receptors assume their laminar pattern only in the second half of gestation (Lidow and Rakic, 1994) when axons originating from the geniculate nucleus begin to invade the cortical plate (Rakic, 1976, 1977a). This timing of developmental events, theoretically, allows for the possibility that thalamic input exerts its influence on the monoamine receptor distribution in the cortex. However, since, in the anophthalmic monkeys, the remaining neurons in the lateral geniculate nucleus do not segregate into $\mathrm{M}$ - and P-related moieties (Rakic, 1988; Suner and Rakic, unpublished observation), it is inexplicable that neuronal targets of the geniculate axon terminals in the cortex display such a clear cyto- and chemoarchitectonic segregation into $\mathrm{M}$ - and P-related sublayers. One possibility is that the occipital cortex in primates has an intrinsic developmental program essential for forming some of the species-specific cytoarchitectonic features, including formation of $\mathrm{M}$ and $\mathrm{P}$ sublayers in area 17 and distribution pattern of monoamine receptors. An alternative possibility is that geniculate neurons generate such a program independently of the cues from the retinal photoreceptors, and induce formation of these cortical features via the remaining thalamocortical input. The appropriate tests of these two possibilities have not been performed in any primates. However, relevant studies were recently done in the somatosensory system of developing rodents. In this species, the block of impulse activity, originated from the ventroposterolateral thalamocortical afferents by NMDA antagonists, does not disrupt the emergence of a normal barrel pattern characteristic of somatosensory cortex (Schlaggar et al., 1994).

Comparison with previous studies. The present work is the first quantitative autoradiographic analysis of the distribution of monoamine receptors in the cerebral cortex of experimentally induced anophthalmic animals. Earlier reports on the effect of extrinsic factors on neurotransmitter receptor maturation in the neocortex dealt mainly with the effect of visual deprivation, such as eyelid suture, dark rearing, or monocular enucleation at postnatal ages (Schliebs et al., 1982a,b; Wilkinson et al., 1983; Aoki 
et al., 1986; Aurich and Bigl, 1988; Shaw and Cynader, 1988; Chalmers and McCulloch, 1989; Reynolds and Bear, 1989). Furthermore, most of these studies were carried on in nonprimate species in which the primary visual cortex has different connections, areal division, laminar pattern, and synaptic organization. For example, the horder of area 17 , which is very sharp and prominent in primates, is either faint or nonexistent in carnivores and rodents (Lund, 1988). Furthermore, the visual cortex in the rhesus monkey has a more elaborate areal and laminar distribution of neurotransmitter-specific innervation than in any subprimate species examined thus far (for review, see Rakic et al., 1988). There is some evidence that the cellular mechanisms underlying differentiation of the visual cortex in primate are initiated earlier and display a more autonomous course than in the nonprimate species (Rakic, 1988; Kennedy and Dehay, 1993). It is therefore possible that the chemoarchitecture of this highly differentiated cortical subsystem in primates had acquired a new developmental strategy during evolution. However, despite species-specific differences in timing and sequence of developmental cellular events, and the use of different experimental procedures, and in many instances different radioligands, a comparison between the present results and the data of receptor bindings in enucleates and dark-reared animals in other species is instructive.

Review of the literature shows that dark rearing does not usually interfere with development of monoaminergic receptors in the visual cortex. For example, several investigators report no changes in the density of $\beta$-adrenergic receptors in visually deprived rats and cats (Schliebs et al., 1982a,b; Wilkinson et al., 1983; Aoki et al., 1986; Aurich and Bigl, 1988). It was also shown that monocular deprivation after birth does not alter either $\alpha 1$ - or $\alpha 2$-adrenergic receptors in rat visual cortex (Aurich et al., 1989). Finally, while Aurich et al. (1985) observed an increase in density of 5-HT -serotonergic sites in dark-reared rats, Murphy et al. (1980) were unable to detect changes in these sites in similar conditions. Since previous studies of monoamine receptor distribution involved less drastic, later sustained, and shorter lasting manipulations of visual input, we expected that enucleation performed before midgestation, and involving both retinas, would have a more significant affect on monoamine receptors. The results, however, revealed a remarkably normal distribution and density of monoamine-specific ligands examined.

A normal development of monoamine receptors observed in visual deprivation studies stands in contrast to significant changes in the density and distribution that were reported for several other classes of neurotransmitter receptors. Thus, it has been shown that eyelid suture in newborn kittens reduces substantially the concentration of GABA receptors (Shaw and $\mathrm{Cy}$ nader, 1988). Likewise monocular enucleation in the rat causes a reduction in ${ }^{3} \mathrm{H}$-glutamate binding in both superficial and deep layers of the rat and cat visual cortex (Chalmers and McCulloch, 1989; Reynolds and Bear, 1989). Unilateral eye suture in the developing rat can result in changes in the pattern and decrease in density of distribution of muscarinic $\mathrm{ACh}$ receptors (Walsh et al., 1989). Finally, normal laminar distribution of $M_{1}$ and $M_{2}$ muscarinic ACh receptor subtypes in the cat visual cortex can be prevented by elimination of cortical afferents in early postnatal life (Prusky and Cynader, 1990). Thus, it is likely that some other neurotransmitter systems may depend more on visual stimulation for their development and maintenance.

Implications for congenital anophthalmia. The present results are relevant to understanding the timing and pathogenesis mech- anisms of secondary anophthalmia in which retinas in the embryo degenerate soon after the eye primordium has been formed. Both in secondary congenital anophthalmia in humans (Bolton, 1900; Brunquell et al., 1984) and in prenatally enucleated monkeys (Rakic, 1988; Rakic et al., 1991), the laminar pattern of the striate cortex appears to develop normally, but the overall size of the striate area is considerably smaller. The present results show, in addition, that the striate cortex of the occipital lobe can develop and maintain a normal pattern and density of major monoamine receptor subtypes in the absence of activity or contact-mediated transfer of molecular cues from the photoreceptors of the retina.

What is the function of the monoamine receptors in the visual cortex deprived of its normal retinal input? There is evidence that the presumptive visual cortex is electrically and metabolically active. For example, the occipital pole, occupied normally by the primary visual cortex in congenitally blind humans, displays a considerable level of metabolic activity in the absence of visual stimulation (Veraat et al., 1990). In contrast, the same region in individuals who lose their sight during adulthood displays low activity under the very same conditions. The high metabolic activity may be sustained by the aberrant synapses developed and maintained in the absence of visual stimulation. For example, the density of synapses per unit volume of neuropil in the striate cortex attains and retains normal levels in anophthalmic monkeys (Bourgeois and Rakic, 1994). Finally, formation of synapses in the striate cortex in premature monkeys in which visual stimulation begins at an earlier age proceeds on the same schedule as in controls, suggesting that the initial phases of synaptogenesis in the visual cortex may be independent of visual stimulation (Bourgeois et al., 1989). Taken together, these findings suggest that certain species-specific, areaspecific aspects of synaptic and chemical architecture of the cerebral cortex can develop and be maintained independently of visual experience. Therefore, the affect of impulse activity from the periphery may have an effect mostly on the selection and stabilization of already formed synapses.

\section{References}

Aoki C, Kaufman D, Rainbow TC (1986) The ontogeny of the laminar distribution of $\beta$-adrenergic receptors in the visual cortex of cats, normally reared and dark-reared. Dev Brain Res 27:109-111.

Arimatsu Y, Mixamoto M, Nihonmatsu I, Hirata K, Uratani Y, Hatanka Y, Takiguchi-Hoyashi K (1992) Early regional specification for a molecular neuronal phenotype in the rat neocortex. Proc Natl Acad Sci USA 89:8879-8883.

Aurich M, Bigl V (1988) A critical period of the development of $\beta$-adrenergic receptor binding in the visual system of rat during visual deprivation. Int $\mathbf{J}$ Dev Neurosci 6:351-357.

Aurich M, Schliebs R, Bigl V (1985) Serotonergic receptors in the visual system of light-deprived rats. Int J Dev Neurosci 3:285-290.

Aurich M, Schliebs R, Stewart MG, Rudolph E, Fischer H-D, Bigl V (1989) Adaptive changes in the central noradrenergic system in monocular deprived rats. Brain Res Bull 22:173-180.

Barbe MF, Levitt P (1993) The early commitment of fetal neurons to limbic cortex. J Neurosci 11:519-533.

Berry M, Hollingsworth J (1973) Development of isolated neocortex. Experientia 29:204-207.

Bolton JS (1900) the exact histological localization of the visual area of the human cerebral cortex. Philos Trans R Soc (Lond) 193:165202.

Bourgeois J-P, Rakic P (1994) Changing of synaptic density in the primary visual cortex of the rhesus monkey from fetal to adult stage. J Neurosci 13:2801-2820.

Bourgeois J-P, Jastreboff PJ, Rakic P (1989) Synaptogenesis in visual cortex of normal and preterm monkeys: evidence for intrinsic regu- 
lation of synaptic overproduction. Proc Natl Acad Sci USA 86:42974301 .

Brodmann K (1909) Vergleichende Lokalisationslehre der Grosshirninde. Leipzig: Barth.

Brooksbank BWL, Martinez M, Atkinson DJ, Balas R (1978) Biochemical development in the human brain. I. Some parameters of cholinergic system. Dev Neurosci 1:267-284.

Brown RM, Goldman-Rakic PS (1977) Catecholamines in neocortex of rhesus monkeys: regional distribution and ontogenetic development. Brain Res 124:550-576.

Brunquell IJ, Papale JH, Horton JC, Williams RS, Zgrabik MJ, Albert DM, Hedley-Whyte T (1984) Sex-linked hereditary bilateral anophthalmos. Pathologic and radiologic correlation. Arch Ophthalmol (Copenh) 102:108-113.

Chalmers DT, McCulloch J (1989) Reduction in $\left[{ }^{3} \mathrm{H}\right]$ glutamate binding in the visual cortex after unilateral orbital enucleation. Neurosci Lett 97:298-304.

Cohen-Tannoudji M, Babinet C, Wassef M (1994) Early intrinsic regional specification of the mouse somatosensory cortex. Nature 368 : 460-463.

Dehay C, Horsburgh O, Berland M, Killackey H, Kennedy H (1989) Maturation and connectivity of the visual cortex in monkey is altered by prenatal removal of retinal input. Nature 337:265-267.

Dehay C, Horsburgh G, Berland M, Killackey H, Kennedy H (1991) The effects of bilateral enucleation in the primate fetus on the parcellation of visual cortexes. Dev Brain Res 62:137-141.

DeValois RL, DeValois KK (1975) Neural coding of color. In: Handbook of perception: seeing (Carterette EC, Freedman MP, eds). New York: Academic.

DeYoe EA, Van Essen DC (1988) Concurrent processing streams in monkey visual cortex. Trends Neurosci 11:219-226.

Fallon JH, Loughlin SE (1987) Monoamine innervation of cerebral cortex and theory of the role of monoamines in cerebral cortex and basal ganglia. In: Cerebral cortex, Vol 6 (Jones EG, Peters A, eds), pp 41-128. New York: Plenum.

Felleman DJ, Van Essen DC (1991) Distributed hierarchical processing in the primate cerebral cortex. Cereb Cortex 1:1-47.

Ferri RT, Levitt P (1993) Cerebral cortical progenitors are fated to produce area-specific neuronal population. Cereb Cortex 3:187-198.

Hendrickson A, Rakic P (1977) Histogenesis and synaptogenesis in the dorsal lateral geniculate nucleus (LGd) of the fetal monkey brain. Anat Rec 187:602.

Hubcl DH, Wiesel TN, LeVay S (1977) Plasticity of ocular dominance columns in monkey striate cortex. Philos Trans $\mathrm{R}$ Soc Lond [Biol] 278:377-409.

Jones EG (1990) Determinants of the cytoarchitecture of the cerebral cortex. In: Signals and sense. Local and global order in perceptual maps (Edelman EG, Gall WE, Cowan MW, eds), pp 3-49. New York: Wiley.

Kaiserman-Abramov I, Graybiel A, Nauta WH (1983) Thalamic projection to area 17 in a congenitally anophthalmic mouse strain. Neuroscience 5:41-52.

Kennedy H, Dehay C (1993) Cortical specification of mice and men. Cercb Cortex 3:171-186.

Kennedy H, Dehay C, Horsburg G (1990) Striate cortex periodicity. Nature 384:494

Kind P, Murphy DM, Sengpiel F, Blakemore C (1993) Disruption of generation of layer 4 in cat area 17 retards geniculate axon segregation but not the emergence of cytochromoxidase "blobs." Soc Neurosci Abstr 19:893.

Kuljis R, Rakic P (1989) Hypercolumns in primate visual cortex develop in the absence of cues from photoreceptors. Proc Natl Acad Sci USA 87:5303-5306.

Lauder JM (1993) Neurotransmitters as growth regulator signals: role of receptors and second messengers. Trends Neurosei 16:233-240.

Lauder JM, Wallace JA, Krebs H, Petrusz P, McCarthy K (1982) In vivo and in vitro development of serotonergic neurons. Brain Res Bull 9:605-625.

LaVail MM, Rapaport DH, Rakic P (1991) Cytogenesis in the monkey retina. J Comp Neurol 309:86-114.

Levitt PR, Rakic P, Goldman-Rakic PS (1984) Region-specific distribution of catecholamine afferents in primate cerebral cortex: a fluorescence histochemical analysis. J Comp Neurol 225:1-14.

Lidow MS, Rakic P (1992) Postnatal development of monoaminergic neurotransmitter receptors with primate neocortex. Cereb Cortex 2:401-415.

Lidow MS, Rakic P (1994) Unique profiles of the $\alpha 1-, \alpha 2$ - and $\beta$-adrenergic receptors in the developing cortical plate and transient embryonic zones of the rhesus monkey. J Neurosci 14:4064-4078.

Lidow MS, Goldman-Rakic PS, Rakic P, Gallager DW (1988) Differential quenching and limits of resolution in autoradiograms of brain tissue labeled with ${ }^{3} \mathrm{H}^{-125} \mathrm{I}$ - and ${ }^{14} \mathrm{C}$-compounds. Brain Res 459:105119.

Lidow MS, Goldman-Rakic PS, Gallager DW, Rakic P (1989a) Quantitative autoradiographic mapping of serotonin $5-\mathrm{HT}_{1}$ and $5-\mathrm{HT}_{2}$ receptors and serotonin uptake sites in neocortex of rhesus monkey. $\mathbf{J}$ Comp Neurol 280:27-42.

Lidow MS, Goldman-Rakic PS, Gallager DW, Geschwind DH, Rakic P (1989b) Distribution of major neurotransmitter receptors in the primary motor and somatosensory cortex of rhesus monkey. Neuroscience 32:609-627.

Lidow MS, Goldman-Rakic PS, Rakic P (1991a) Synchronized overproduction of neurotransmitter receptors in diverse regions of the primate cerebral cortex Proc Natl Acad Sci USA 88:10218-10221.

Lidow MS, Goldman-Rakic PS, Gallager DW, Rakic P (1991b) Distribution of dopaminergic receptors in the primate cerebral cortex: quantitative autoradiographic analysis using $\left[{ }^{3} \mathrm{H}\right]$ raclopride, $\left[{ }^{3} \mathrm{H}\right] \mathrm{spip}-$ erone and $\left[{ }^{3} \mathrm{H}\right] \mathrm{SCH} 23390$. Neuroscience 40:657-671.

Livingstone M, Hubel DH (1988) Segregation of form, color, movement, and depth: anatomy, physiology and perception. Science 240: $740-749$.

Lund J (1973) Organization of neurons in the visual cortex of area 17 of the monkey (Macaca mulatta). J Comp Neurol 147:455-496.

Lund J (1988) Anatomical organization of macaque monkey visual cortex. Annu Rev Neurosci 11:253-288.

Mattson MP (1988) Ncurotransmitters in the regulation of neuronal cytoarchitecture. Brain Res Rev 13:179-212.

McConnell SK (1991) The generation of cortical diversity in the central nervous system. Annu Rev Neurosci 14:269-300.

Morrison JH, Foote SL, O'Connor D, Bloom FE (1982) Laminar, tangential and regional organization of noradrenergic innervation of monkey cortex: dopamine $\beta$-hydroxidase immunocytochemistry Brain Res Bull 9:309-319.

Murphy S, Uzbekow MG, Rose SP (1980) Changes in serotonin receptors in different brain regions after exposure to dark-reared rats. Neurosci Lett 17:317-321.

Nishimura Y, Rakic P (1985) Development of the rhesus monkey retina. I. Emergence of the inner plexiform layer and its synapses. J Comp Neurol 241:420-434.

O'Leary DDM, Schlaggar BL, Tuttle R (1994) Specification of neocortical areas and thalamocortical connections. Annu Rev Neurosci 17:419-439.

Parnavelas JG, Blue ME (1982) The role of noradrenergic system in formation of synapses in the visual cortex of the rat. Dev Brain Res 3:140-144.

Peters A, Jones EG, eds (1984) Cerebral cortex, Vol 1, Cellular components of the cerebral cortex. New York: Plenum.

Prusky G, Cynader M (1990) The distribution of $\mathbf{M}_{1}$ and $\mathbf{M}_{2}$ muscarinic acetylcholine receptor subtypes in developing cat visual cortex. Dev Brain Res 56:1-12.

Rakic P (1972) Mode of cell migration to the superficial layers of fetal monkey neocortex. J Comp Neurol 145:61-84.

Rakic P (1974) Neurons in rhesus monkey visual cortex: systematic relation between time of origin and eventual disposition. Science 183: $425-427$.

Rakic P (1976) Prenatal genesis of connections subserving ocular dominance in the rhesus monkey. Nature 261:467-471.

Rakic P (1977a) Prenatal development of the visual system in the rhesus monkcy. Philos Trans R Soc Lond [Biol] 278:245-260.

Rakic P (1977b) Genesis of the lateral geniculate nucleus in the rhesus monkey. J Comp Neurol 176:23-52.

Rakic P (1988) Specification of cerebral cortical areas. Science 241: 170-176.

Rakic P (1991) Radial unit hypothesis of cerebral cortical evolution. Exp Brain Res [Suppl] 21:25-43.

Rakic P, Goldman-Rakic PS (1985) Use of fetal neurosurgery for experimental studies of structural and functional brain development in nonhuman primates. In: Prenatal neurology and neurosurgery 
(Thompson RA, Green JR, Johnson SD, eds), pp 1-15. New York: Spectrum.

Rakic P, Riley KP (1983) Overproduction and elimination of retinal axons in the fetal rhesus monkey. Science 209:1441-1444.

Rakic P, Gallager D, Goldman-Rakic PS (1988) Areal and laminar distribution of major neurotransmitter receptors in the monkey visual corlex. J Neurosci 8:3670-3690.

Rakic P, Suñer I, Williams RW (1991) A novel cytoarchitectonic area induced experimentally within the primate visual cortex. Proc Natl Acad Sci USA 88:2083-2087.

Reynolds I, Bear MF (1989) NMDA receptor development in the visual cortex of cats. Soc Neurosci Abstr 15:2.

Schein ST, deMonasterio FM (1987) Mapping of retinal and geniculate neurons onto striate cortex of macaque. J Neurosci 7:996-1009.

Schlaggar BL, Fox K, O'Leary DDM (1994) Postsynaptic control of plasticity in developing somatosensory cortex. Nature 364:623-626.

Schliebs R, Bigl V, Beisold D (1982a) Development of muscarinic receptor binding in the visual system of monocularly deprived and dark-reared rats. Neurosci Res 7:1181-1198.

Schliebs R, Burgoyne RD, Bigl V (1982b) The effect of visual deprivation of $\beta$-adrenergic receptors in the visual centers of the rat brain. J Neurochem 38:1038-1043.

Shatz CJ (1990) Impulse activity and patterning of connections during CNS development. Neuron 5:745-756.

Shaw C, Cynader M (1988) Unilateral eyelid suture increases $\mathrm{GABA}_{\mathrm{A}}$ receptors in visual cortex. Dev Brain Res 40:148-153.

Sokal RR, Rohlf FJ (1981) Biometry. New York: Friedman.

Teller DY, Boothe R (1979) Development of vision in infant primates. Trans Ophthalmol Soc UK 99:333-337.

Ts'o DY, Gilbert CD (1988) The organization of chromatic and spatial interactions in the primate striate cortex. J Neurosci 8:1712-1727.
Veraat C, DeVolder AG, Wanet-Defalque MC, Bol A, Michel C, Goffinet AM (1990) Glucose utilization in human visual cortex is abnormally elevated in blindness of early onset but decreased in blindness of late onset. Brain Res 510:115-164.

Walsh C, Schliebs R, Bigi V (1989) Effect of early visual pattern deprivation on development and laminar distribution of cholinergic markers in rat visual cortex. In: Central cholinergic synaptic transmission (Frotscher M, Misgeld V, eds), pp 295-304. Basel: Birkhauser.

Whitaker-Azmatia P (1991) Role of serotonin and ollıer neurotranımitter receptors in brain development: basis for developmental pharmacology. Pharmacol Rev 43:553-561.

Wiesel TN (1982) Postnatal development of the visual cortex and influence of environment. Nature 299:583-591.

Wiesel TN, Hubel D (1966) Spatial and chromatic interactions in the lateral geniculate body of the rhesus monkey. J Neurophysiol 29: $11150-11156$.

Wikler KC, Rakic P (1991) Emergence of the photoreceptor mosaic from a protomap of early-differentiating cones in the primate retina Nature 351:397-400.

Wikler KS, Rakic P (1994) An array of early-differentiating cones precedes the emergence of the photoreceptor mosaic in the fetal monkey retina. Proc Natl Acad Sci USA 91:6534-6538.

Wilkinson M, Shaw C, Khan I, Cynader M (1983) Ontogeny of $\beta$-adrenergic binding sites in kitten visual cortex and the effects of visual deprivation. Dev Brain Res 7:349-352.

Williams RW, Rakic P (1988) Elimination of neurons in the rhesus monkey's lateral geniculate nucleus during development. J Comp Neurol 272:424-436.

Willians RW, Borodkin M, Rakic P (1991) Growth cone distribution patterns in optic nerve of fetal monkeys: implication for mechanisms of axonal guidance. J Neurosci 11:1081-1094. 